\title{
EL QUIJOTE DE LOS SUPERHÉROES M. Night Shyamalan y la consolidación del cine de superhéroes como género cinematográfico
}

Francisco J. ORTIZ

(Universidad de Alicante)

\section{RESUMEN:}

En lo que va de siglo XXI, las películas basadas en cómics protagonizados por superhéroes vienen experimentando un crecimiento exponencial en cuanto a popularidad y rendimiento en taquilla sin parangón en la historia del cine; tanto es así que se viene planteando la posibilidad de que nos encontremos ante un nuevo género cinematográfico con sus propios estilemas temáticos y visuales. Por otra parte, el interés generalizado que despiertan estas historias ha terminado generando propuestas afines pero de carácter original; esto es, creaciones fílmicas no basadas en un material previo. De entre todas estas producciones de nuevo cuño destacan tres títulos dirigidos por el cineasta M. Night Shyamalan, cuyas respectivas tramas interrelacionadas conforman un relato que puede interpretarse como una relectura del Quijote de Cervantes en clave superheroica, y que ha servido para consolidar un nuevo género audiovisual -no olvidamos la televisión, medio en el que en buena medida germinaron las primeras semillas del mismo- reconocido como tal.

Palabras clave: secuela, universo compartido, Eastrail 177 Trilogy, Unbreakable Trilogy, Glass Trilogy.

\section{EL CALDO DE CULTIVO DE UN NUEVO GÉNERO CINEMATOGRÁFICO (1978-1999)}

Las primeras versiones de carne y hueso de los personajes superheroicos de las viñetas, consideradas hoy en conjunto como artefactos audiovisuales de estética naif, llegaron al público (estadounidense primero, del resto del mundo después) a través de la pequeña pantalla y en formato de Saturday serial («serie de los sábados») a lo largo de la década de los cuarenta: el primero de aquellos seriales en blanco y negro -que además del material de base bebían también de otros productos previos ajenos al género como Flash Gordon (1936) o Buck Rogers (1939), ambos de ciencia ficción- fue Adventures of Captain Marvel 
(1941); a este le siguieron otros como Batman (1943), Captain America (1944) o Superman (1948). Tiempo después, la irrupción del color traería consigo un estallido pop en la serie Batman de 1966; seguida de The Amazing Spider-Man y The Incredible Hulk, las discretas adaptaciones de Marvel Comics emitidas ambas a partir de 1977.

Pero sería Superman, considerado el primer superhéroe en ver la luz en el terreno del cómic en Action Comics \#1 con fecha de junio de 1938, quien protagonizaría cuatro décadas más tarde la primera adaptación cinematográfica para la gran pantalla de un cómic de superhéroes tal y como se entiende este concepto. Nos referimos, claro está, a Superman (1978), dirigida por Richard Donner y protagonizada por el malogrado Christopher Reeve; un film que daría pie a tres secuelas de interés decreciente (1980, 1983 y 1987) y un spin-off menor protagonizado por la prima del Hombre de Acero: Supergirl (1984).

Poco más de una década después de aquel estreno de relevancia capital, la sociedad asistiría a un renacer del género en los cines gracias al éxito internacional de la adaptación del segundo superhéroe, Batman, que fue creado como contrapunto del anterior en mayo de 1939 en las páginas de Detective Comics \#27. En efecto, la cinta Batman (1989), dirigida por Tim Burton y protagonizada por Michael Keaton, disfrutó de un éxito tal en la taquilla de todo el mundo que terminó generando a lo largo de los años noventa del siglo pasado, además de tres secuelas oficiales, un número considerable de nuevas adaptaciones (algunas adscritas al género superheroico sin ambages, otras con algunos elementos comunes a él): Captain America (1990), Dick Tracy (1990), Teenage Mutant Ninja Turtles (1990), The Rocketeer (1991), The Crow (1994), The Fantastic Four (1994), The Mask (1994), The Shadow (1994), Timecop (1994), Judge Dredd (1995), Tank Girl (1995), Barb Wire (1996), The Phantom (1996), Men in Black (1997), Spawn (1997), Steel (1997), Blade (1998) o la paródica Mystery Men (1999) son algunos de los ejemplos que demuestran la fiebre por los héroes de los tebeos que se vivió durante aquel período.

No obstante, puede señalarse el año 2000 como un verdadero punto y aparte previo a la fundación de lo que hoy en día nadie duda en considerar como un género cinematográfico por derecho propio, o al menos como un subgénero o una vertiente más dentro del cine fantástico o el de ciencia ficción: el cine de superhéroes. Escogemos esta fecha por ser la del estreno de X-Men, primer film basado en un cómic del género (concretamente, de la editorial Marvel Comics) cuyos excelentes resultados en taquilla generaron una serie de sinergias que perduran hasta el día de hoy y que -pese a finalizaciones de contratos, traspasos de derechos legales y abandonos personales varios- no presentan visos de concluir; tan solo, en todo caso, revelan una clara tendencia a redefinirse y/o reiniciarse.

Resulta curioso que fuese en ese mismo año 2000 cuando el cineasta estadounidense de origen indio M. Night Shyamalan estrena Unbreakable (en España, El protegido), película que en un primer momento fue saludada como un thriller fantástico cuya pretensión primordial parecía ser la de repetir la exitosa fórmula de la inmediatamente anterior The Sixth Sense (1999) con otra fábula fantástica de sorprendente twist final ${ }^{1}$. Esto, sin dejar de ser cierto en parte, pronto se antojó como un juicio impreciso o insuficiente para explicar lo que de

1 Como señalan Gómez-Tarín y Rubio Alcover, "Shyamalan iba a quedar definitivamente asociado a la poética del twist (el final-sorpresa) merced a [...] El protegido (Unbreakable, 2000). Ello no significa que esta asociación de un recurso más bien populista con su sello no fuera en parte injusto, ya que eso era tan cierto como que tanto esta pieza como El sexto sentido acreditaban otros rasgos bastante menos frecuentes y cómodos para con el espectador medio de un cine mainstream [...] como son un ritmo inusitadamente moroso y una melancolía a tono con el tema, sumamente lúgubre» (2013: 5). 
forma sibilina escondía aquella cinta: un relato que, si bien era inédito hasta la fecha, podía adscribirse al género que nos ocupa; y que además, con el paso del tiempo, se revelaría también como el germen de una mitología original y propia².

\section{UNBREAKABLE (2000): LA FORJA DE UN (SUPER)HÉROE}

La sinopsis de esta primera aproximación de Shyamalan al género superheroico es la siguiente: David Dunn (Bruce Willis) es padre de familia y trabaja como vigilante de seguridad en un estadio deportivo de Filadelfia. Tanto su vida familiar como su carrera profesional están en crisis: su matrimonio con Audrey (Robin Wright Penn) hace aguas, lo que parece que empieza a afectar a su hijo Joseph (Spencer Treat Clark); y la decisión de mudarse en solitario implica encontrar otro trabajo en otra ciudad. En uno de sus trayectos realizados a tal fin, el tren en el que viaja descarrila con resultados devastadores: todos los pasajeros fallecen, con la única excepción de David. Es entonces cuando entra en escena Elijah Price (Samuel L. Jackson), propietario de una galería especializada en el noveno arte que padece una extraña patología: osteogénesis imperfecta, conocida comúnmente como «enfermedad de los huesos de cristal», y que le convierte en un ser extremadamente frágil. Este, convencido de que David representa el extremo diametralmente opuesto a él mismo, tratará de convencerle de que ha sobrevivido a la catástrofe porque cuenta con habilidades especiales parecidas a las de los superhéroes de los cómics que tanto venera y que para él son «una nueva forma de saber oculto» (Navarro, 2004: 52).

Unbreakable se estrenó tan solo un año después de The Sixth Sense, por lo que es fácil intuir que se trataba de un proyecto largamente acariciado y con muchas horas de trabajo detrás en el momento en el que arranca su preproducción. Un proyecto que, además y ya desde entonces, formaba parte de una propuesta más amplia y ambiciosa: la de una trilogía. Pueden desmentirse fácilmente aquellos rumores que apuestan a que la relación de las posteriores Split (2016) y Glass (2019) con Unbreakable es una vinculación que solo existe a posteriori: en su estudio dedicado al realizador y publicado en 2012 -esto es, cuatro años antes del estreno de Split y siete del de Glass-, Ramón Monedero ya señalaba: «Night estaba tan convencido de que El protegido iba a ser un éxito tan o más descomunal que El sexto sentido que en un primer momento, la película iba a ser la primera parte de una trilogía. Su raíz brotaba de la cultura de los cómics, y todos sabemos lo bien que suelen funcionar las adaptaciones del cómic al cine, al menos durante los últimos años» (2012: 108).

Por tanto, y aunque sus secuelas fueron tardías y llegaron -en la línea del cine de su autor, muy dado a las sorpresas- cuando nadie las esperaba ya, Unbreakable puede y debe verse como la primera entrega de una saga... por más que tras el estreno del film, y quizá porque su resultado en taquilla no fue tan satisfactorio como el de The Sixth Sense, el propio Shyamalan llegase a manifestar: «no soy la clase de persona que quiere hacer secuelas o ser

2 Algunas voces han acusado a Shyamalan de basarse en trabajos ajenos sin reconocerlo: es el caso del director de cine (y guionista de historietas ocasional) Kevin Smith, que señaló ciertas similitudes entre Unbreakable y el cómic Mage: The Hero Discovered de Matt Wagner; o el crítico de cine Elvis Mitchell, que atendió a una cuestión menor comparando el aspecto del protagonista de la primera vestido con su impermeable verde con El Espectro de DC Comics. No obstante, ninguna de estas acusaciones llegó a más en términos legales. (Vid. Alarcón, 2011: 250). 
conocido sólo por una clase de películas. Quiero que cada uno de mis films sean originales y distintos [sic]» (2012: 108).

En efecto, la cinta que nos ocupa puede verse como el inicio de una obra en tres actos que responde a un concepto básico del cómic de superhéroes: el llamado secret origin («origen secreto»); esto es, el relato del nacimiento y la constitución del héroe en cuestión ${ }^{3}$. Un protagonista que, en esta ocasión, nace como consecuencia de los actos de quien será su némesis y por tanto villano principal de la función ${ }^{4}$.

También debemos al citado Ramón Monedero esta acertada reflexión a propósito de la primera «película de superhéroes» de Shyamalan:

El protegido es, esencialmente, una película de perspectivas, o mejor aún, de nuevas perspectivas; y la primera de ellas la podemos apreciar en la misma forma en la que el film se aproxima al mundo de los superhéroes. En realidad, la película de M. Night Shyamalan poco tiene que ver con las habituales adaptaciones que el cine de Hollywood hace de los cómics. Si la relación, que desde prácticamente su origen, ha mantenido el cine con los cómics se ha asentado fundamentalmente en traspasar, con mayor o menor fortuna, el espíritu de un cómic a la gran pantalla, El protegido aboga en cambio por una aproximación en perspectiva al propio concepto del cómic, como creación artística en sí misma. Esta es una de las razones por la que la película, al menos en su momento, no fue del todo asimilada por los fans de los cómics y por extensión, [sic] por los admiradores del cine de superhéroes en general. El protegido no perseguía tanto plasmar en la pantalla una sucesión de viñetas convertidas en imágenes en movimiento como plantear un acercamiento algo más abstracto a la propia mecánica, a la propia filosofía de los cómics ${ }^{5}$ (2012: 112).

3 Estas primeras aventuras de un personaje, no siempre narradas en su primera aparición impresa en el ámbito de los cómics, han sido trasladadas en repetidas ocasiones al cine: baste recordar el origen de Superman, representado en la citada Superman y en Man of Steel (2013); el de Batman, quizá el más recreado tanto en las viñetas como en la gran pantalla, en presente o a modo de flashback, y visto en filmes como la mencionada Batman, Batman Begins (2005) o Batman v Superman: Dawn of Justice (2016); o el de Spiderman, narrado en la cinta homónima de 2002 y, en cierta medida, en The Amazing Spider-Man (2012). Cuando el relato abarca también las primeras andanzas como justiciero del personaje principal, se suele emplear otra etiqueta muy habitual en los cómics del género: la de year one («año uno»); siendo la historia más recordada la de Batman: Year One del guionista Frank Miller y el dibujante David Mazzucchelli.

4 La presencia de un giro de guion que revela que el superhéroe se origina como consecuencia de la acción del supervillano es un recurso que ya pudo verse en el citado Batman de Tim Burton, donde se descubría finalmente que el personaje de Jack Napier / Joker (Jack Nicholson) había sido el asesino de los padres de un pequeño Bruce Wayne, futuro Batman, años atrás. Una coincidencia esta que es invención de los guionistas Sam Hamm y Warren Skaaren, y que por tanto no proviene del cómic adaptado.

5 También tendría en vista un objetivo igual de ambicioso el director Ang Lee a la hora de realizar su particular aportación al género: Hulk (2003), donde el relato adquiría en ocasiones la apariencia visual de viñetas mediante el recurso de la split screen o «pantalla partida». El resultado, si bien menos satisfactorio que en el caso de Shyamalan, no mereció los varapalos generalizados que recibió en su día por parte de la crítica especializada y muy especialmente de los espectadores. Mejor tratada en líneas generales fue Watchmen (2009), en la que el realizador Zack Snyder trató de calcar en buena medida muchas de las viñetas del cómic homónimo de Alan Moore y Dave Gibbons. 
En efecto, desde su mismo arranque la película no oculta en ningún momento su deuda con el universo de los cómics impresos, pues empieza con un texto introductorio que, entendido como imagen en su totalidad, puede recordar a las cartelas de la narrativa gráfica secuencial [Figura 1] $]^{6}$.

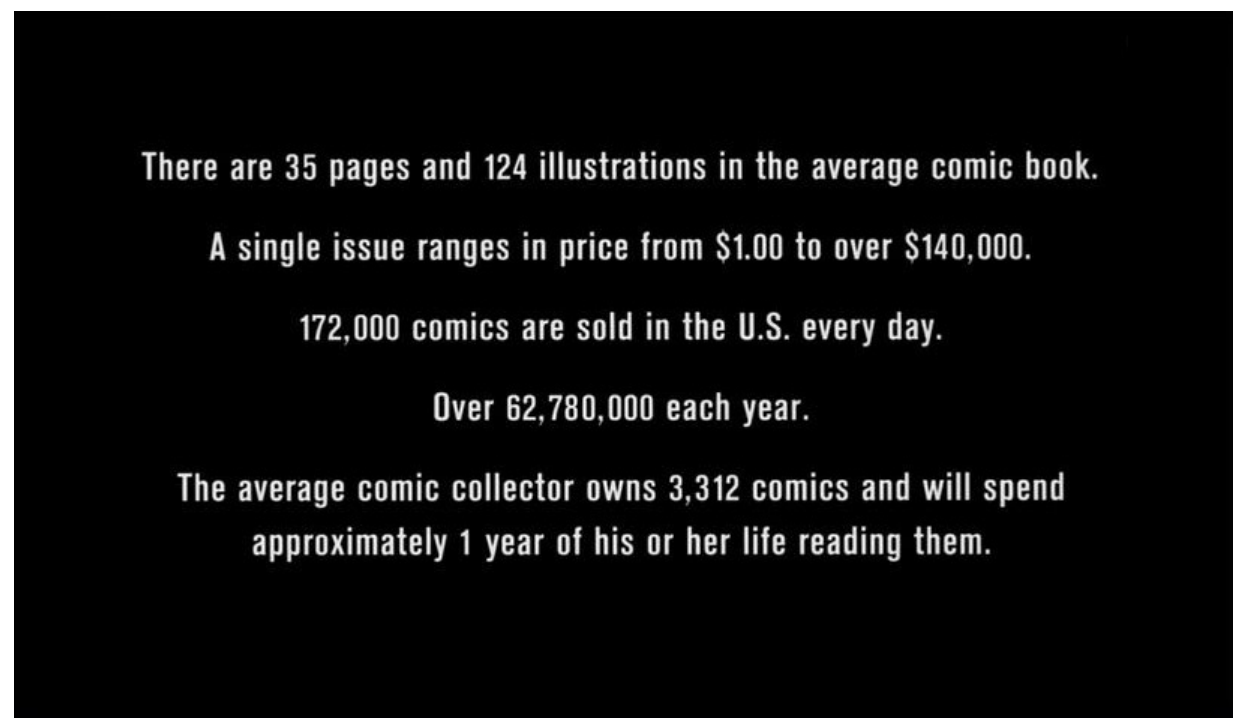

Fig. 1. Texto introductorio del film Unbreakable

A continuación, aparece en escena, en manos de un joven Elijah, un número del apócrifo Active Comics (obvio homenaje al Action Comics que acogió las primeras aventuras de Superman en los quioscos) [Figura 2]; un ejemplar en el que se advierte la leyenda Limited Edition («Edición limitada») que servirá para dar nombre a la galería de arte especializada en cómics que regentará su dueño muchos años después [Figura 3].

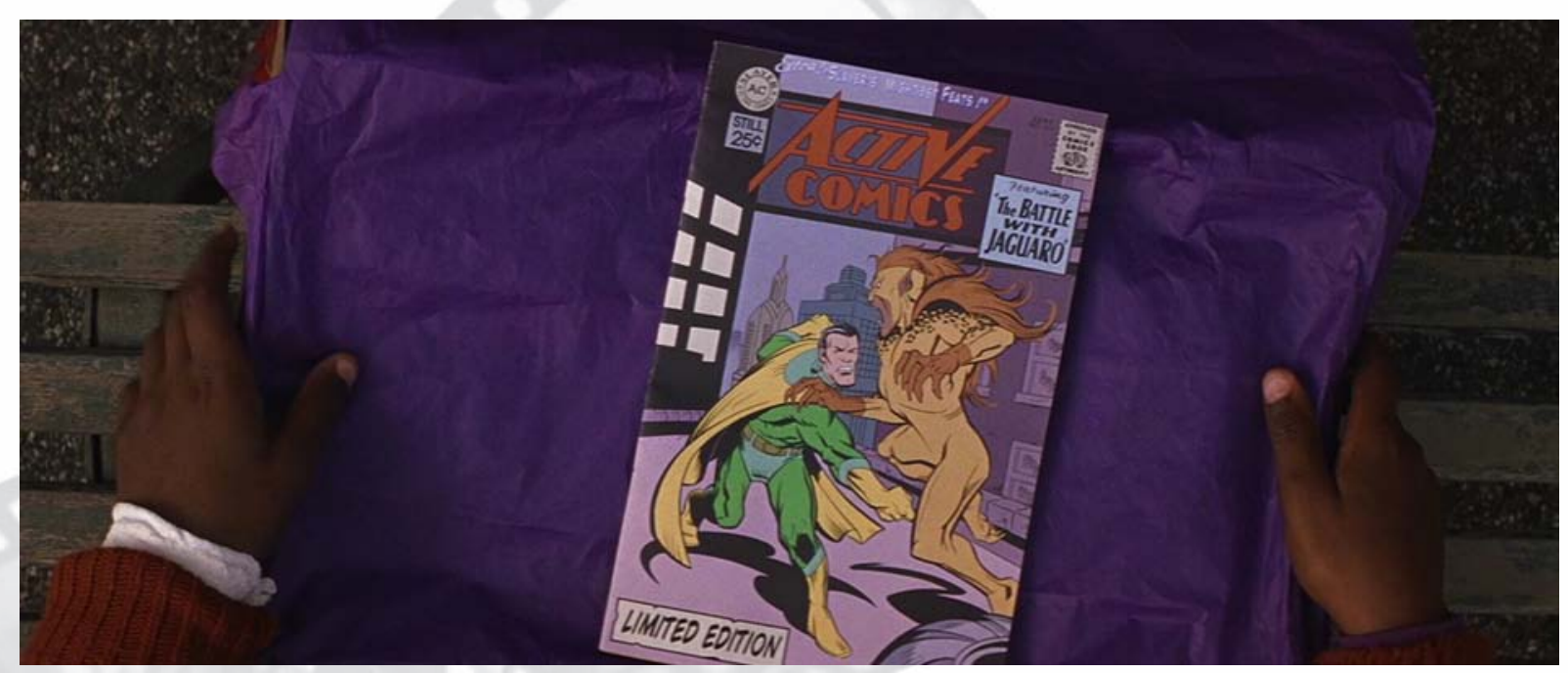

Fig. 2. Un joven Elijah recibe un cómic como regalo de su madre

6 Traducción al castellano: «Cada cómic tiene una media de 35 páginas y 124 ilustraciones. El precio de cada ejemplar oscila entre 1 y 140.000 dólares. En Estados Unidos se venden 172.000 cómics al día. Unos 62.780.000 al año. Cada coleccionista posee una media de 3.312 cómics y pasaría aproximadamente un año de su vida leyéndolos». 


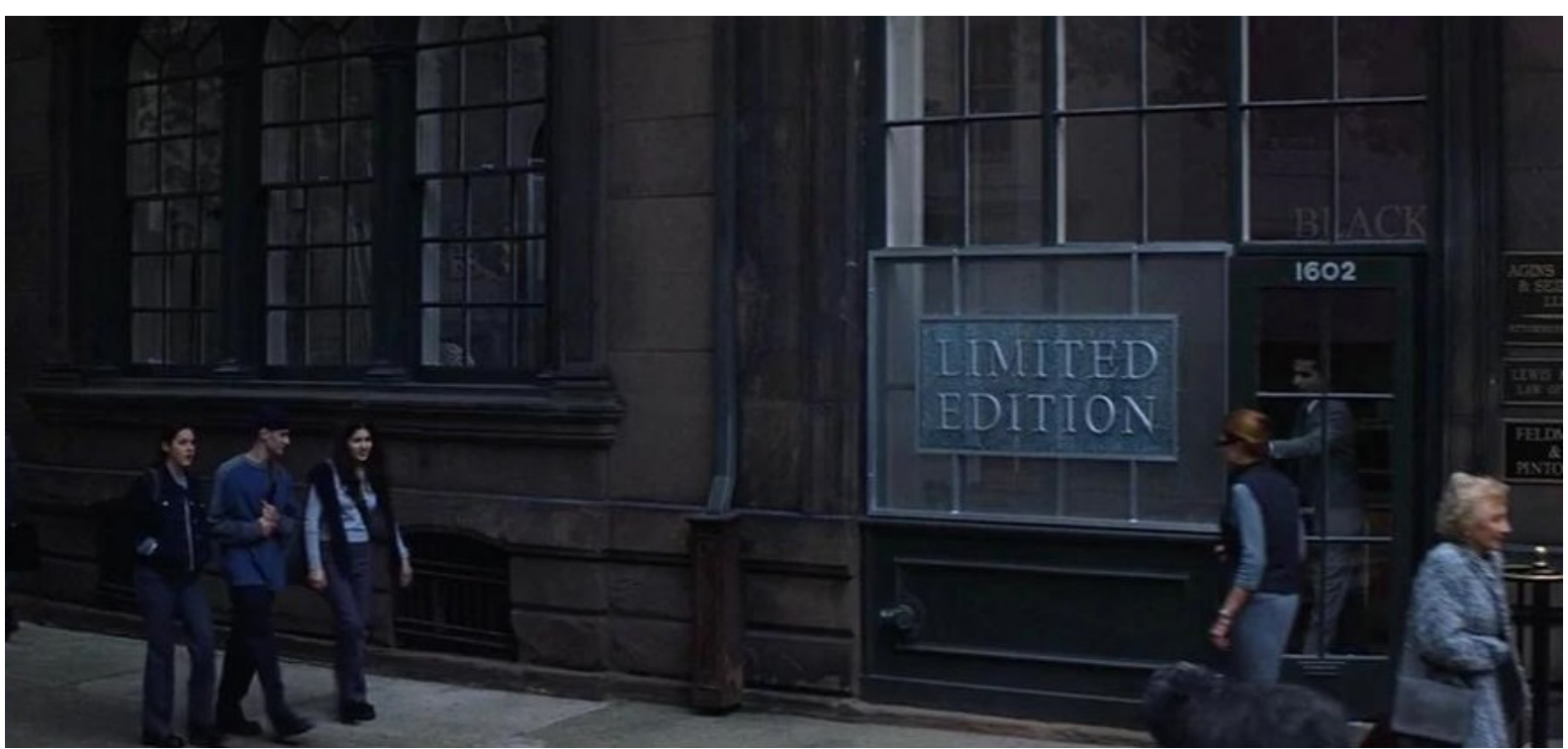

Fig. 3. Fachada de Limited Edition, la galería de arte propiedad de Elijah Price

Por añadidura, y además de aludir al tema de la dualidad y los extremos contrapuestos (que alcanza, como veremos luego, al propio diseño conceptual de toda la trilogía como tal), los continuos reflejos de personajes en espejos, cristales, ventanas o pantallas de televisión sugieren los encuadres de las viñetas propios del cómic. Por si esto fuera poco, la construcción de muchos de los planos en los que aparecen tanto David Dunn como Elijah Price responde también a la presencia de un eje de simetría vertical e invisible que divide la pantalla en dos, subrayado por los sempiternos colores que definen a ambos personajes: verde y púrpura, respectivamente [Figura 4].

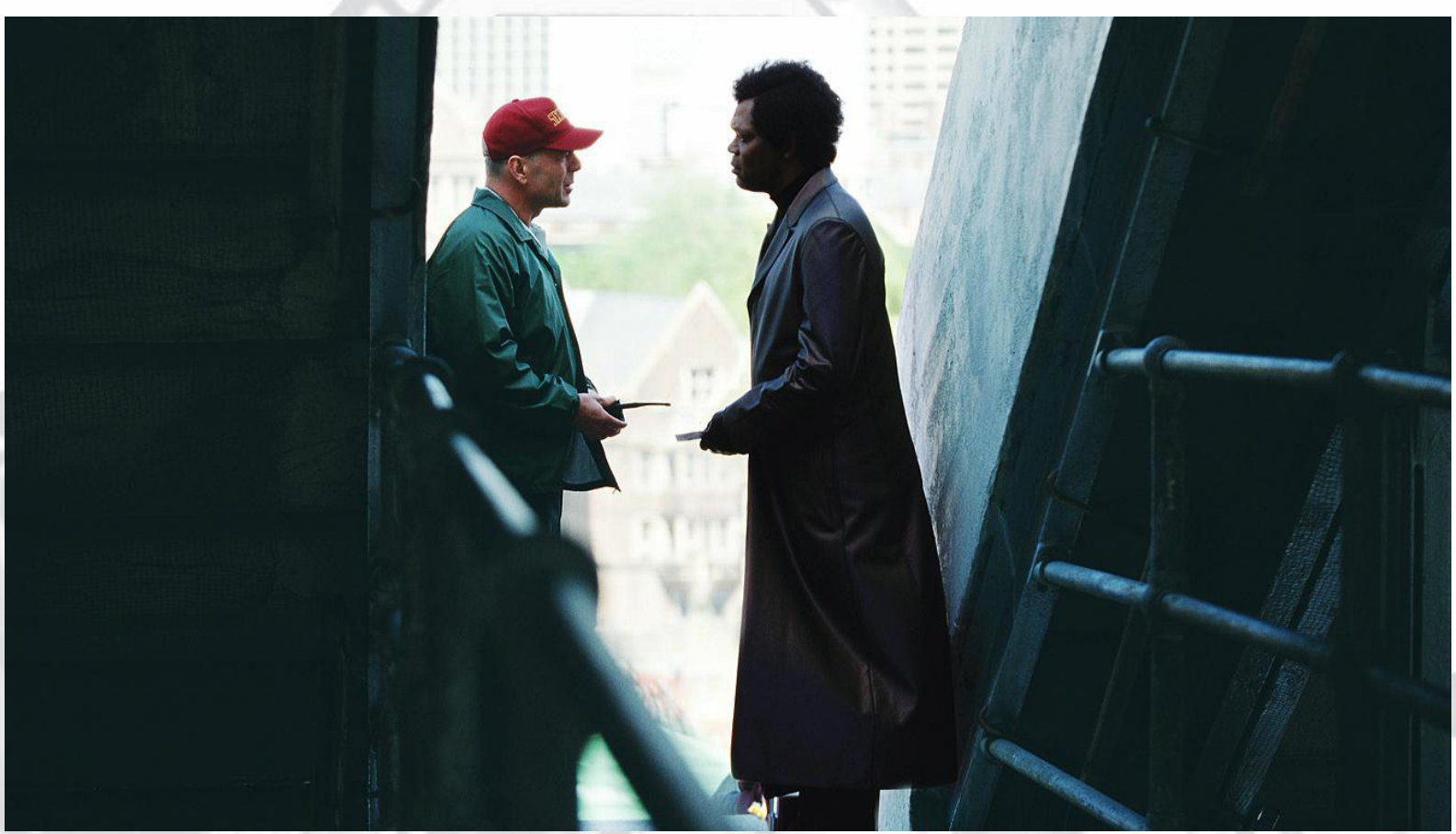

Fig. 4. Elijah trata de convencer a David de que este posee poderes sobrehumanos 
Por otra parte, y ya en términos puramente argumentales, de la historia de Unbreakable y de su personaje principal deben destacarse una serie de elementos comunes a los cómics de superhéroes:

a) Un nombre aliterativo: el protagonista de Unbreakable responde al nombre de David Dunn, una aliteración que se origina como recurso en el universo de la animación para niños: baste recordar a Mickey Mouse (el ratón Mickey), Donald Duck (el pato Donald), Bugs Bunny, Road Runner (el Correcaminos) o Mighty Mouse (Super Ratón), este último una parodia infantil del propio Superman. Este recurso fonético es muy habitual en el universo de los cómics de superhéroes, ya se manifieste en los nombres civiles de los personajes y/o en sus respectivos alias de superhéroe o supervillano. El fallecido Stan Lee, guionista y editor en jefe de Marvel y cocreador de muchos de sus personajes más populares, explicitó su querencia por los nombres aliterativos como un recurso mnemotécnico para recordarlos mejor: citemos algunos como Reed Richards / Mr. Fantástico, Susan Storm / Mujer Invisible, Peter Parker / Spiderman, Bruce Banner / Hulk, Scott Summers / Cíclope, Matt Murdock / Daredevil, Stephen Strange / Doctor Extraño, Silver Surfer (en España, Estela Plateada), etcétera. En cuanto a su rival DC, ténganse en cuenta sobre todo los casos del álter ego civil de Superman, Clark Kent; su enemigo más encarnizado: Lex Luthor; o cuatro mujeres con las que en un momento u otro el primero mantuvo una relación sentimental: Lois Lane, Lana Lang, Lori Lemaris y Wonder Woman, esta última un personaje protagonista per se. Sin olvidar a otros superhéroes de la compañía como Blue Beetle, Mister Miracle, Beast Boy, J'onn J'onzz / Detective Marciano, Wally West / Flash, Buddy Baker / Animal Man, Guy Gardner / Linterna Verde, Boston Brand / Deadman, Zatanna Zatara o grupos como Teen Titans (Jóvenes Titanes) o Suicide Squad (Escuadrón Suicida).

b) Un alias: al tratarse del relato del origen del héroe, además reacio a asumir su condición como tal, David Dunn no cuenta con un alias superheroico propiamente dicho. No será hasta una de las primeras secuencias de la posterior Glass que descubramos que la prensa ha decidido rebautizarlo (¿definitivamente?) con el alias de The Overseer («El Protector»)

c) Unos poderes específicos: David Dunn presenta dos poderes claramente diferenciados: por un lado, invulnerabilidad (no recuerda haber enfermado nunca, por ejemplo); por otro, una suerte de cognición extrasensorial a partir del contacto físico con aquellos que han obrado mal. Estos poderes (especialmente el primero) se han contemplado ya, por supuesto, entre la amplísima lista de habilidades censadas en el ámbito del cómic de superhéroes.

d) Un aliado: esta figura está representada en el film por Elijah Price, si bien en el universo de los cómics suelen jugar dicho rol personajes en edad adolescente con el fin de potenciar la identificación del lector juvenil. De esta clase de personajes, llamados sidekicks en el mercado anglosajón y compañeros en el hispano, muy probablemente sea el ejemplo más célebre Robin, el Chico Maravilla, discípulo

7 En esta secuencia, una de las más humorísticas del film, Joseph Dunn le recuerda a su padre que antes había recibido sobrenombres más ridículos, como The Tip-Toe Man («El Hurtadillas») o The Enforcer («El Merodeador»). 
de Batman en muchas de sus aventuras y visto en el cine en las adaptaciones dirigidas por Joel Schumacher. También podemos mencionar, en el seno de Marvel, compañeros como Bucky Barnes luchando codo a codo con el Capitán América o Rick Jones acompañando a diversos héroes en sus andanzas.

e) Una némesis principal: aunque luego se ampliará la nómina con la presentación del personaje central de Split, y dado que la naturaleza como villano de Elijah Price / Don Cristal no se revela hasta el acto final, la trama cuenta con un supervillano en realidad menor: el llamado The Orange Man («El Hombre Naranja»), un peligroso psicópata que ataca a familias enteras en su propia casa y al que El Protector derrotará en su primera incursión nocturna como superhéroe.

f) Un traje específico: aunque desde sus mismos orígenes la vestimenta de los superhéroes en las viñetas que les vieron nacer ha hecho gala de diseños ostentosos y colores llamativos, en su aproximación hiperrealista al género Shyamalan rechaza esta opción; no obstante, no reniega convertir el chubasquero con capucha de su personaje principal en un traje de superhéroe sui generis, pero reconocible como tal.

g) Un punto débil: como le ocurre a David Dunn con un elemento tan común como el agua, todo superhéroe que se precie tiene un talón de Aquiles. Este recurso se creó con la doble intención de humanizar a personajes que hasta el momento eran poco menos que dioses y posibilitar que sus vidas corrieran algún riesgo, facilitando así la identificación con el lector y enriqueciendo la emoción de sus aventuras. El paradigma de este recurso narrativo es la kriptonita en todas sus variantes: un mineral extraterrestre que debilita a Superman, le arrebata sus poderes, altera su conducta e incluso puede llegar a matarlo.

h) Una identidad secreta: en una de las últimas secuencias del film, ambientada en la cocina de su hogar, David Dunn dirige a su hijo Joseph un discreto gesto con el que le pide que mantenga en secreto lo que sabe de los poderes y las acciones heroicas de su progenitor. En efecto, la mayoría de superhéroes de los cómics se cuidan mucho de revelar públicamente cuál es su identidad civil, con el fin de proteger a sus seres queridos de posibles acciones criminales por parte de sus enemigos. Las dualidades Clark Kent / Superman, Bruce Wayne / Batman o Peter Parker / Spiderman son ejemplos paradigmáticos de ello.

Pese a las expectativas puestas de cara a su estreno, y aunque quedó lejos de resultar un fracaso, Unbreakable estuvo muy lejos de ser tan rentable como The Sixth Sense, y Shyamalan se vio obligado a aparcar durante un largo tiempo la continuación de la historia tal y como la tenía pensada. En el ínterin que se produjo hasta el estreno de Split en 2016, el realizador dirigiría con resultados desiguales siete películas más, todas ella adscritas de una forma u otra al género fantástico o al terror pero ajenas al mundo de los superhéroes: Signs (2002), The Village (2004), Lady in the Water (2006), The Happening (2008), The Last Airbender (2010), After Earth (2013) y The Visit (2015). Sería precisamente durante la gestación de esta última que su asociación con Blumhouse, la productora de Jason Blum especializada en cine de terror de presupuesto medio y buen rendimiento en taquilla, abriría la puerta a retomar la historia de David Dunn y Elijah Price... aunque en un primer momento nadie se enterase de ello. 


\section{SPLIT (2016): EL NACIMIENTO DE UN (SUPER)VILLANO}

Split (estrenada en España con el título de Múltiple) nos presenta a un individuo que, como Elijah Price, padece un trastorno, este mental, de carácter inusual: el de personalidad múltiple. Veintitrés son, inicialmente, las identidades conocidas de quien luego sabremos que en realidad se llama Kevin Wendell Crumb (James McAvoy); a estas parece que se sumará en breve una más, la más temible de todas: The Beast («La Bestia»). La llegada de esta es lo que más temen tres chicas adolescentes: Casey (Anya Taylor-Joy), Claire (Haley Lu Richardson) y Marcia (Jessica Sula), secuestradas por Dennis, otra de las personalidades más peligrosas de Kevin. Mientras las tres muchachas tratan de escapar de su cautiverio, la veterana doctora Karen Fletcher (Betty Buckley), especialista en dicho trastorno mental y particularmente interesada en cómo este afecta al organismo vivo que lo sufre, trata de ayudar a su paciente.

Split ha sido considerada como la primera «secuela secreta» de la historia del cine ${ }^{8}$, pues su naturaleza de continuación no se revela durante la preparación y/o la promoción del film; de hecho, ni siquiera se establece el vínculo entre ella y su predecesora en los primeros compases del relato. Muy al contrario, el nexo entre ambas no sale a la luz hasta la última escena de la película, apenas unos segundos antes de que hagan acto de presencia los títulos de crédito finales, en lo que Roberto García-Ochoa Peces califica de «revolucionario giro final» (AA.VV., 2019: 366). Además, vista y analizada la trilogía en su totalidad, este episodio central es en términos argumentales el más ajeno al género superheroico; $y$, si se elimina su última secuencia, funciona como un film de terror psicológico stricto sensu.

Esta decisión, en cierta medida arriesgada pero que por otro lado dota a la propuesta de un valor histórico indiscutible, no desentona en una filmografía como la de Shyamalan, proclive -además de a los sorprendentes twists finales, como ya se ha visto- a una reflexión a propósito de los géneros cinematográficos que se suele manifestar a partir de dichos giros inesperados: recordemos que Unbreakable y Signs tampoco se promocionaron como sendas muestras de «cine de superhéroes» y «cine de ciencia ficción» respectivamente, sino como thrillers fantásticos y de misterio en la línea de The Sixth Sense; y, muy especialmente, que la decepción generalizada que supuso para buena parte de su público la por otro lado magistral The Village se debe a que su adscripción al género del cine de terror -tal y como fue publicitada- quedó en entredicho al revelarse su verdadera naturaleza de drama que reflexionaba sobre cuestiones político-sociales.

Pese a todo lo dicho, y al margen del interés extradiegético de tan inusual propuesta, nuestro análisis de Split debe focalizarse en su pertenencia a una mitología propia que arranca en Unbreakable y culmina (al menos por el momento) en Glass. De hecho, y como ya hemos visto, el film corresponde al segundo acto que quedó fuera durante la redacción del guion definitivo de Unbreakable, dado que Shyamalan no podía olvidarse de narrar el origen del que sería uno de los principales antagonistas del protagonista de aquella. A ello se refiere Tonio L. Alarcón al escribir a propósito de la primera entrega de la trilogía lo siguiente:

8 El especialista Roberto García-Ochoa Peces, antes de ver Glass, plantea también la posibilidad de que Split sea más un spin-off (esto es, un relato derivado) que una secuela o continuación directa de Unbreakable (AA.VV., 2019: 362). Pero tras ver la conclusión de la saga nos decantamos sin lugar a dudas por esta última opción. 
una historia de superhéroes que, siguiendo una estructura clásica de tres actos, se acercaría al género de forma realista y verosímil, desde una perspectiva adulta. Sin embargo, al darle vueltas a la misma, [Shyamalan] se dio cuenta de que le resultaba mucho más interesante el primer segmento, la narración del origen de su personaje principal y de sus antagonistas (2011: 249).

De hecho, y tal como explica el propio Alarcón, «a mediados del año 2010, Shyamalan anunció que había decidido reaprovechar la idea en la que se iba a basar la [...] secuela -y que habría servido para presentar a un nuevo villano- para una de las películas de la serie The Night Chronicles, producidas por Shyamalan a partir de ideas propias, desarrolladas por otros guionistas» (2011: 251). No obstante, de aquel proyecto como tal nunca más se supo, y afortunadamente terminó dando pie al film dirigido por él mismo que ahora nos ocupa; una película cuya razón de ser responde a una doble funcionalidad: servir de carta de presentación de un nuevo supervillano, y al mismo tiempo ejercer de puente entre el «Año Uno» del superhéroe (visto en Unbreakable) y la verdadera conclusión de la historia (narrada en Glass).

Dicho supervillano es Kevin Wendell Crumb, un individuo que cuenta con veinticuatro personalidades diferentes. Al margen de la temible La Bestia, las dominantes parecen ser tres: Barry, un aspirante a diseñador de moda de carácter afable y gestos afeminados cuyo propósito principal parece ser defender a Kevin y mantener a raya al resto de personalidades; Dennis, un sujeto que padece un trastorno obsesivo compulsivo a propósito del orden y la limpieza y que experimenta una peligrosa parafilia: la de obligar a chicas adolescentes a desnudarse y bailar para él; y Patricia, una mujer de comportamiento correcto y educado pero que junto con Dennis rinde culto al advenimiento de La Bestia. Al margen de estas tres identidades, también está muy presente la de Hedwig, un niño de nueve años de gran verborrea y aficionado a bailar temas de hip hop.

Veamos a continuación cómo se plasman en Split los tropos habituales del género ya especificados al hilo de su presencia en Unbreakable:

a) Un nombre aliterativo: el nombre real del protagonista es Kevin Wendell Crumb; un enunciado aliterativo si, siguiendo una costumbre muy arraigada en Estados Unidos, se obvia el segundo nombre tal y como se escucha en el noticiario televisivo del final de Split o en la prensa digital que muestra Glass. Como era de esperar, en el recurrido Universo Marvel el fenómeno de la repetición de fonemas se da también entre los supervillanos, como es el caso del Doctor Doom (en España, Doctor Muerte), Green Goblin (Duende Verde), Otto Octavius / Doctor Octopus, Curt Connors / El Lagarto, Sebastian Shaw o Michael Morbius. Este recurso se manifiesta también en personajes civiles de carácter más o menos secundario dentro del mismo Universo Marvel como J. Jonah Jameson, Robbie Robertson, Betty Brant, Pepper Potts, Happy Hogan, Moira McTaggert, etcétera. Debe mencionarse también que la aliteración del nombre de Kevin Crumb se repite en el de su antagonista ocasional: Casey Cooke, la única de las tres chicas secuestradas que sobrevive al final del relato. 
b) Un alias: aunque las veinticuatro personalidades de su personaje principal responden a otros tantos alias9, Kevin Wendell Crumb es bautizado por la prensa al final del relato con el sobrenombre de The Horde («La Horda»); el cual, obviamente, alude a su personalidad múltiple ${ }^{10}$.

c) Unos poderes específicos: la habilidad del personaje de Kevin que le define como tal es precisamente el DID («Dissociative Identity Desorder»), en español «trastorno de la personalidad múltiple» (o «trastorno de la identidad disociativa»). Al margen de ello, el grueso de personalidades manifestadas por su psique escindida no parecen poseer habilidades especiales ${ }^{11}$; pero la más poderosa de ellas, a la que apodan La Bestia, sí parece ser capaz de sobrevivir a disparos a bocajarro, atravesar gruesos muros, subir paredes sin esfuerzo y desplazarse a una velocidad sobrehumana sobre sus cuatro extremidades.

d) Un aliado: el personaje del film más cercano a este perfil es la Dra. Karen Fletcher, que ejerce de psiquiatra de Kevin y sus múltiples personalidades.

e) Una némesis principal: como ya se ha sugerido, Split es el relato secreto de presentación de la némesis de David Dunn: Kevin Wendell Crumb / La Horda, que por el momento y en el arranque de la posterior Glass tomará el relevo de Elijah Price / Don Cristal como principal enemigo de aquel.

f) Un traje específico: al margen de que cada personalidad elige en la medida de lo posible un atuendo propio para salir al exterior, La Bestia opta -como contraposición a la discreta vestimenta de El Protector y más aún del llamativo atuendo de Don Cristal- por la desnudez como método para expresar su poderoso vigor físico.

g) Un punto débil: los supervillanos de los cómics también suelen tener algún punto débil que los humaniza de cara a los lectores. En el caso de La Horda, como le ocurre a David Dunn con el agua, es escuchar a alguien pronunciar su verdadero nombre. Esto responde a que la toma de conciencia de su identidad primigenia produce un shock mental que le debilita considerablemente.

9 Los créditos finales de Glass recogerán veinte nombres vinculados a la interpretación de James McAvoy, frente a los ocho que mencionan los de Split: Patricia, Dennis, Hedwig, The Beast [La Bestia], Barry, Heinrich, Jade, Ian, Mary Reynolds, Norma, Jalin, Kat, B.T., Kevin Wendell Crumb, Mr. Pritchard, Felida, Luke, Goddard, Samuel y Polly. A estos habría que sumar el de Orwell, presente en Split pero no en Glass. La nómina de veinticuatro identidades diferentes puede completarse con Bernice, Rakel y Ansel gracias a los nombres de los archivos digitales presentes en el escritorio del ordenador de Kevin visto en algunas secuencias de Split. Para más información, consúltese: https://www.culturaocio.com/cine/noticia-glass-hedwig-bestia-todas-personalidadeshorda-habita-dentro-kevin-wendell-crumb-20190122123654.html.

10 En su ensayo «El trauma del villano», el Doctor en Comunicación Audiovisual Aarón Rodríguez Serrano opta por referirse a este personaje tomando por alias el título español de Split: «ese ser escindido al que denominaremos, genéricamente, Múltiple» (AA.W., 2019: 367). Esta decisión, verdaderamente inusual, subraya por otro lado la correspondencia del diseño conceptual de la trilogía con cada uno de los protagonistas de sus distintos capítulos. De este modo, suponemos que Rodríguez Serrano aceptará referirse a David Dunn como Irrompible (traducción literal de Unbreakable), o tal vez incluso como El Protegido (Vid. AA.VV., 2019, pp. 367373).

11 A otro personaje de los cómics del género que padece el mismo trastorno le sucede lo contrario: la joven Kay Challis, alias Crazy Jane, es capaz de manifestar hasta 64 personalidades de las cuales muchas presentan poderes sobrehumanos específicos. Este personaje del Universo DC, creado en 1989 por el guionista Grant Morrison y el dibujante Richard Chase en The Doom Patrol vol. 2 \#19, podría haber supuesto una inspiración para Shyamalan a la hora de concebir a La Horda. Casualmente, Crazy Jane ha contado con una reciente encarnación en imagen real en la serie Doom Patrol, estrenada el mismo año que Glass. 
h) Una identidad secreta: este tropo es en buena media inaplicable a un personaje con más de una veintena de personalidades distintas, pero bien es cierto que en su relación de psiquiatra y paciente con la Dra. Fletcher aquel suele utilizar la amable identidad de Barry; o incluso en alguna ocasión en que en realidad es otra la personalidad dominante, esta se hace pasar por la anterior [Figura 5].

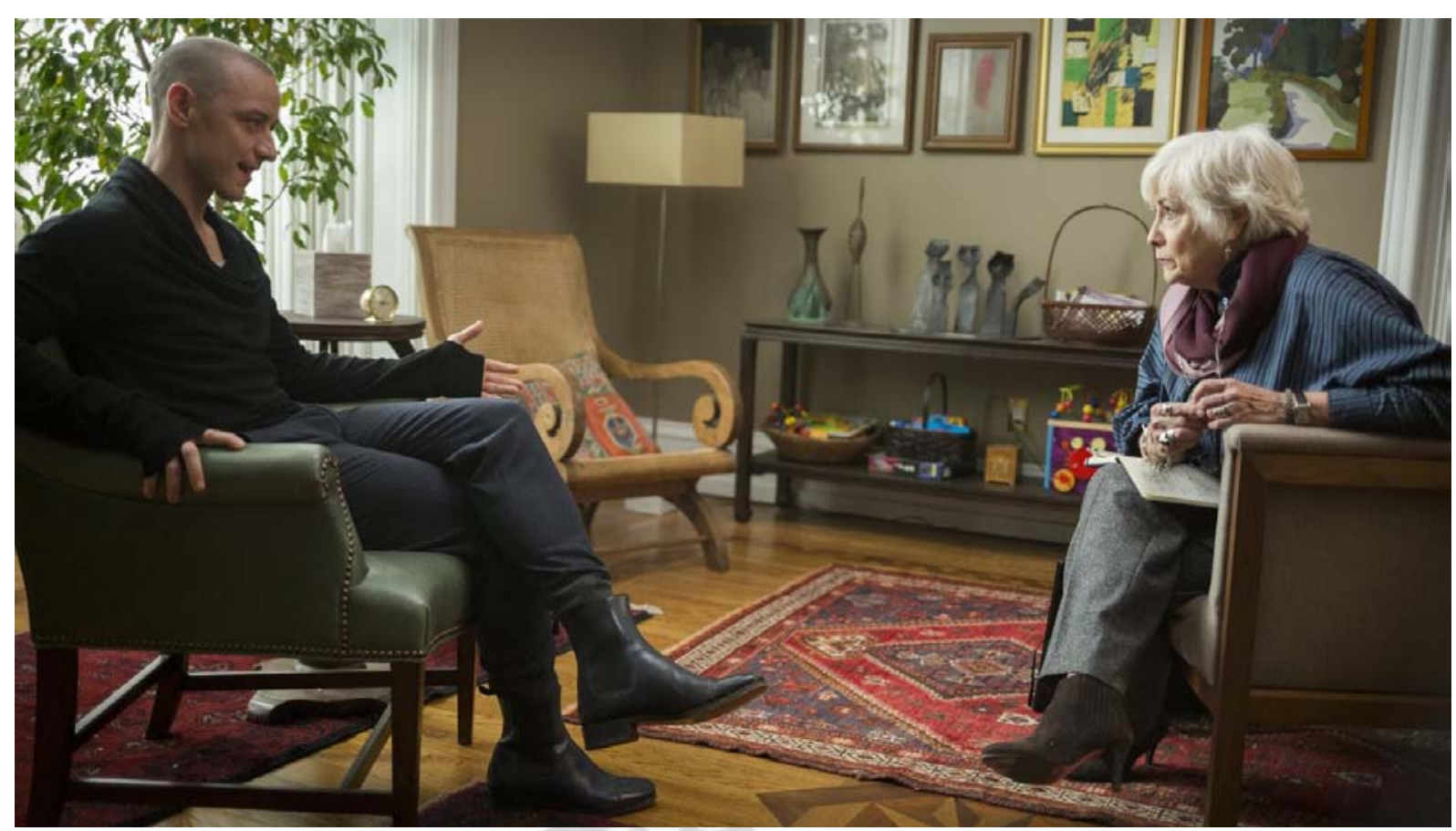

Fig. 5. La Dra. Fletcher dialoga con su paciente y trata de averiguar cuál de sus personalidades es la dominante

A este listado de aspectos se suma uno más, verdaderamente determinante para el asunto tratado, pero que lógicamente no podía aparecer en el «Episodio l» y entonces único de esta saga:

i) Un universo compartido: una de las principales características de los universos superheroicos de los cómics en general, y de los de DC y Marvel en particular, es que sus respectivas historias se desarrollan en un mundo de ficción conectado. Así, en una colección protagonizada por un superhéroe o grupo de superhéroes en particular pueden (y suelen) aparecer personajes de otras cabeceras de la compañía; ya sean estos héroes, villanos o civiles de mayor o menor importancia. Como ya se ha señalado, esta característica de Split solo se revela en su última escena con la aparición sorpresa, a modo de cameo, de Bruce Willis retomando su personaje de Unbreakable [Figura 6] $]^{12}$.

12 Si Glass no se hubiese llegado a rodar jamás, esta secuencia sugeriría igualmente que los personajes de Unbreakable y Split habitan un mismo universo compartido; pero habría quedado como un mero guiño cómplice dirigido al espectador iniciado, al estilo de lo que ha sugerido -pero sin llegar a exprimirlo del todootro cineasta clave de la posmodernidad, Quentin Tarantino, en películas escritas (y no siempre dirigidas) por él como Reservoir Dogs (1992), True Romance (1993), Natural Born Killers (1994), Pulp Fiction (1994), From Dusk Till Dawn (1996), Kill Bill (2003-2004), Inglourious Basterds (2009) o The Hateful Eight (2015). 


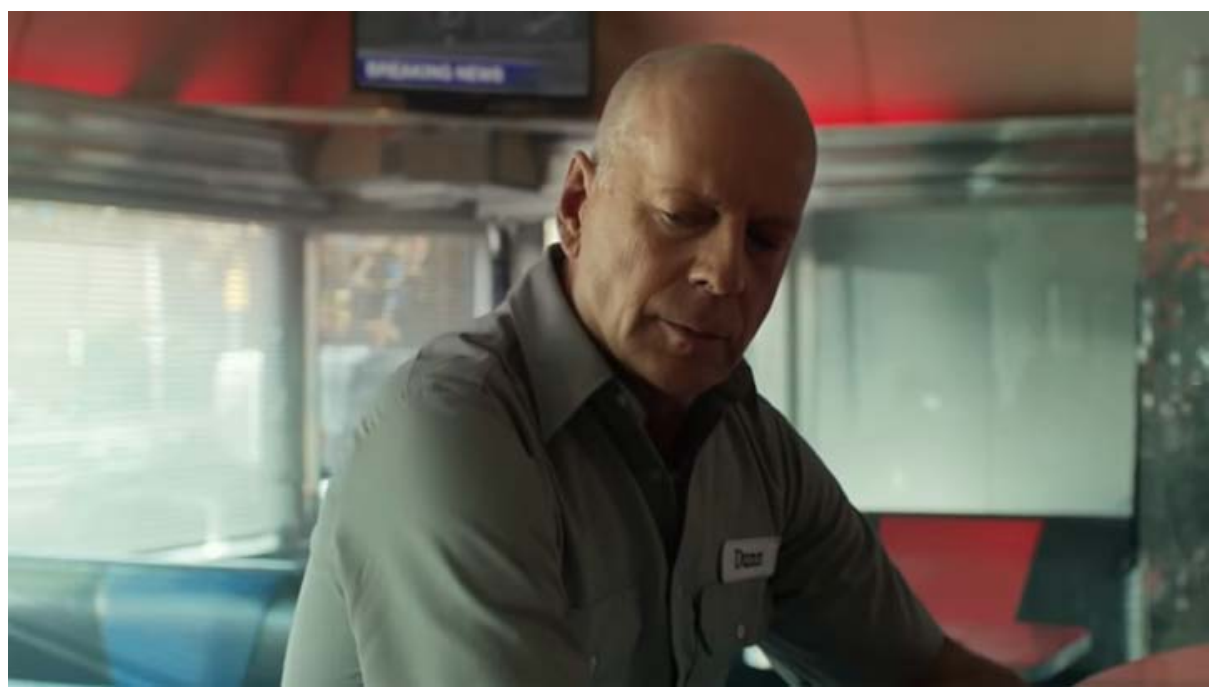

Fig. 6. David Dunn reaparece por sorpresa en la última escena de Split

Sin llegar a convertirse en un fenómeno mundial al nivel de The Sixth Sense, Split funcionó lo suficientemente bien en taquilla como para asegurar la continuación del proyecto superheroico de Shyamalan, de nuevo bajo el auspicio del productor Jason Blum. Pero en esta ocasión no tendríamos que esperar tanto para poder ser testigos del siguiente (y quizás último) capítulo.

\section{GLASS (2019): EL ÚLTIMO TRIUNFO DE UNA MENTE MAESTRA}

Al comienzo de Glass (estrenada en España con el mismo título pero con el añadido del subtítulo Cristal) descubrimos que David Dunn, que sigue ejerciendo de justiciero y al que los periódicos han bautizado como El Protector, ha perdido a su esposa víctima de un cáncer letal. Tampoco sigue trabajando como guarda de seguridad en el estadio, pues unos años atrás decidió montar Dunn Home Security, una empresa propia dedicada a la instalación de sistemas de seguridad doméstica. De vez en cuando le ayuda su hijo Joseph, el cual cursa sus estudios en el mismo instituto al que también acude Casey, la única superviviente del secuestro de tres chicas por parte de una de las personalidades de Kevin Wendell Crumb. Por otro lado, este último sigue libre y ha vuelto a secuestrar a un grupo de jóvenes, esta vez unas animadoras. Cuando David descubra su paradero y trate de detenerlo y rescatar a sus prisioneras, ambos caerán en las manos de las fuerzas de la ley y acabarán bajo la tutela de la doctora Ellie Staple (Sarah Paulson) en el seno de Ravenhill Memorial, una institución mental donde también está recluido desde su detención años atrás otro paciente aparentemente enajenado: Elijah Price.

Al contrario que Split y su condición de secuela secreta, Glass se anunció desde un primer momento no solo como la continuación de las anteriores, sino como el cierre de una trilogía que aglutinaría elementos de aquellas. Pero si bien es cierto que estamos ante una película de protagonismo a tres bandas repartido con los roles de Bruce Willis y James McAvoy, el rey de la función parece ser el Elijah Price encarnado por Samuel L. Jackson desde el mismo título del film, que alude a su álter ego de Mr. Glass («Don Cristal»). Llegado este punto, recordemos la importancia del diseño simétrico de la saga, en la que cada uno de los títulos, siempre una única palabra, está vinculado a cada uno de los personajes 
principales: Unbreakable («irrompible») hace alusión a David Dunn, mientras que Split (que puede traducirse de múltiples maneras: «fragmentado», "escindido», «dividido», "partido», incluso el más genérico «roto») hace referencia a la mente de Kevin Wendell Crumb ${ }^{13}$. Esta continuidad simétrica aparece representada visualmente en los diferentes carteles, tanto los originales estadounidenses como los diseñados para el mercado internacional, de los tres filmes [Figura 7].

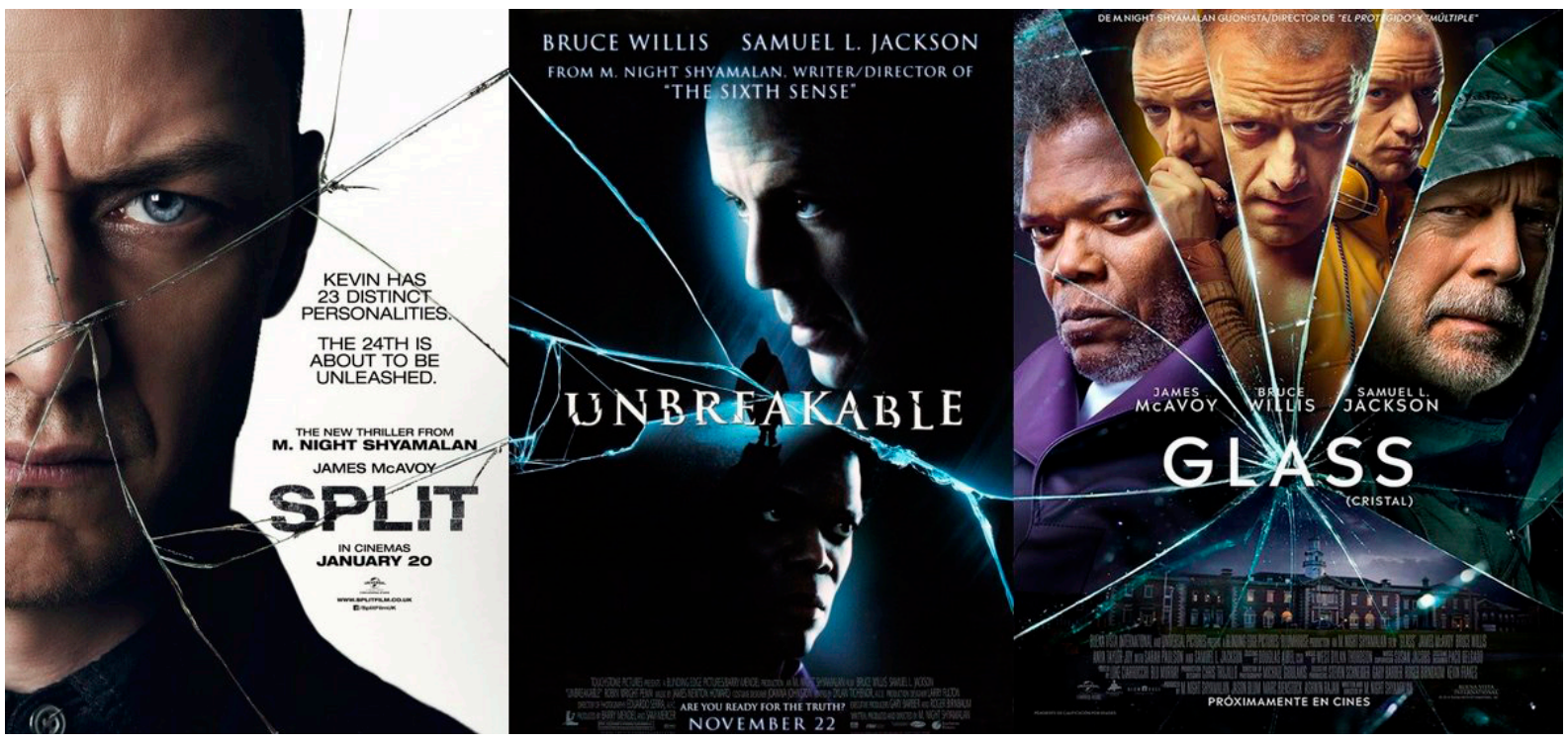

Fig. 7. Los carteles rotos de la trilogía: los estadounidenses de Split y Unbreakable y el español de Glass

Otro elemento clave del film Glass es que en él, al tratarse del cierre de la historia, ya no es necesario que Shyamalan se reserve ninguna información fundamental; por ello, el guionista y realizador salpica todo el relato de homenajes y referencias bastante explícitas al mundo de los cómics. Llama la atención, especialmente, la presencia de tiendas especializadas en cómics como las que salpican la geografía mundial, y muy especialmente los Estados Unidos. Estos espacios se convierten en lugares de reflexión y revelación para los personajes principales, tal y como había ocurrido ya en Unbreakable: en una recordada secuencia de aquella, el personaje de Elijah cobraba conciencia como villano de la historia [Figura 8]. Aquí son Casey, Joseph y la Dra. Staple quienes visitan sucesivamente esta suerte de negocio: la primera encontrará en uno de los cómics adquiridos un personaje similar a La Bestia que tanto la atemorizó en el pasado; el hijo de David hallará la clave para investigar la identidad de los padres de Kevin (mientras al espectador se le sugiere una vez más la dualidad héroe I villano representada con los colores verde y púrpura correspondientes a David y Elijah) [Figura 9]; y la psiquiatra advertirá el verdadero plan que nunca revela una mente maestra como la de Don Cristal.

13 Llegado este punto es de justicia denunciar los muy poco afortunados títulos de ambos filmes en España: salvo que se fuerce el sentido del término para justificar que se trata de alguien salvaguardado por sus propias habilidades, El protegido sugiere la lectura de una conciencia sobrenatural, si no directamente divina, que vela por su protagonista... lo cual es algo inexistente en el relato. Menos grave parece el caso de Múltiple, aludiendo al trastorno de personalidad de su personaje central; pero haberla titulado Fragmentado o Partido mantendría mejor la continuidad con los títulos de Irrompible (este, por otra parte, finalmente desdeñado) y Cristal. 


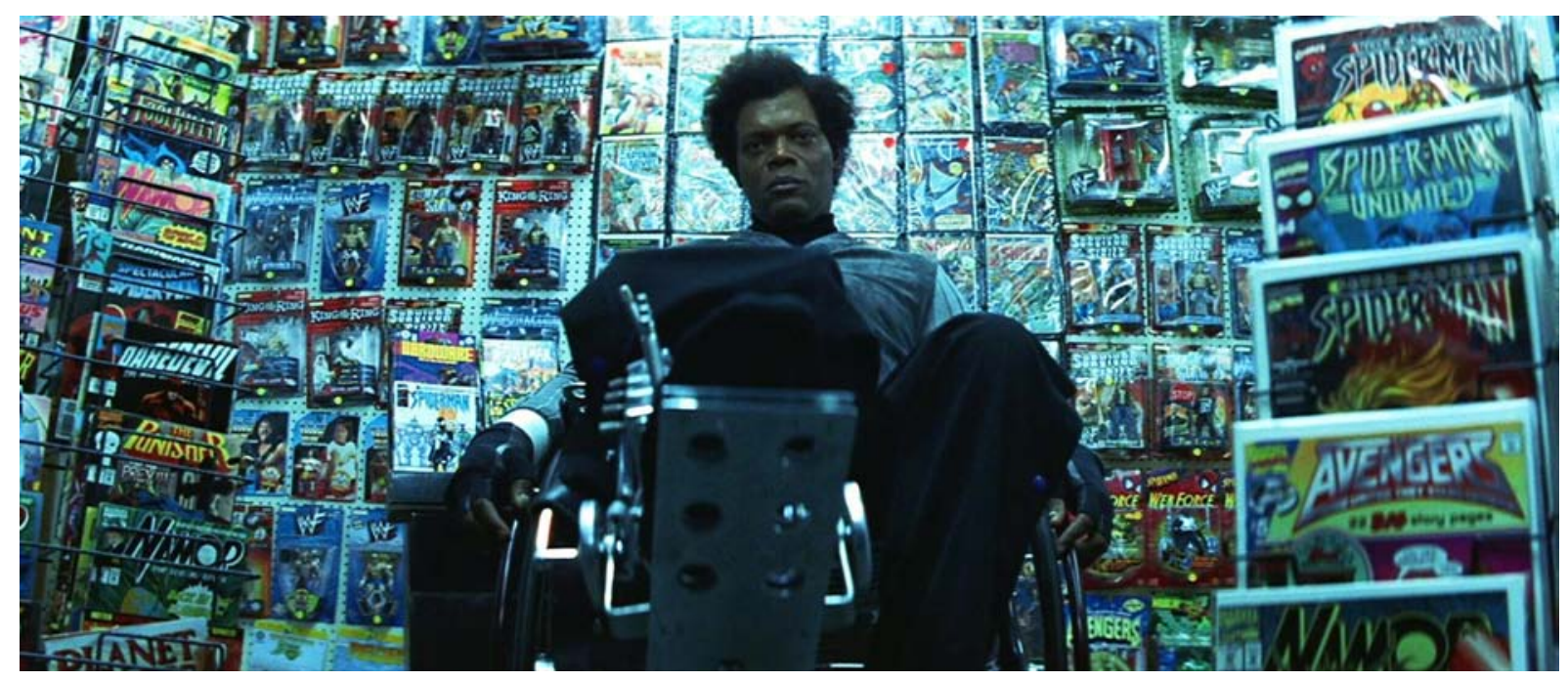

Fig. 8. Elijah Price cobra conciencia de su naturaleza en Unbreakable
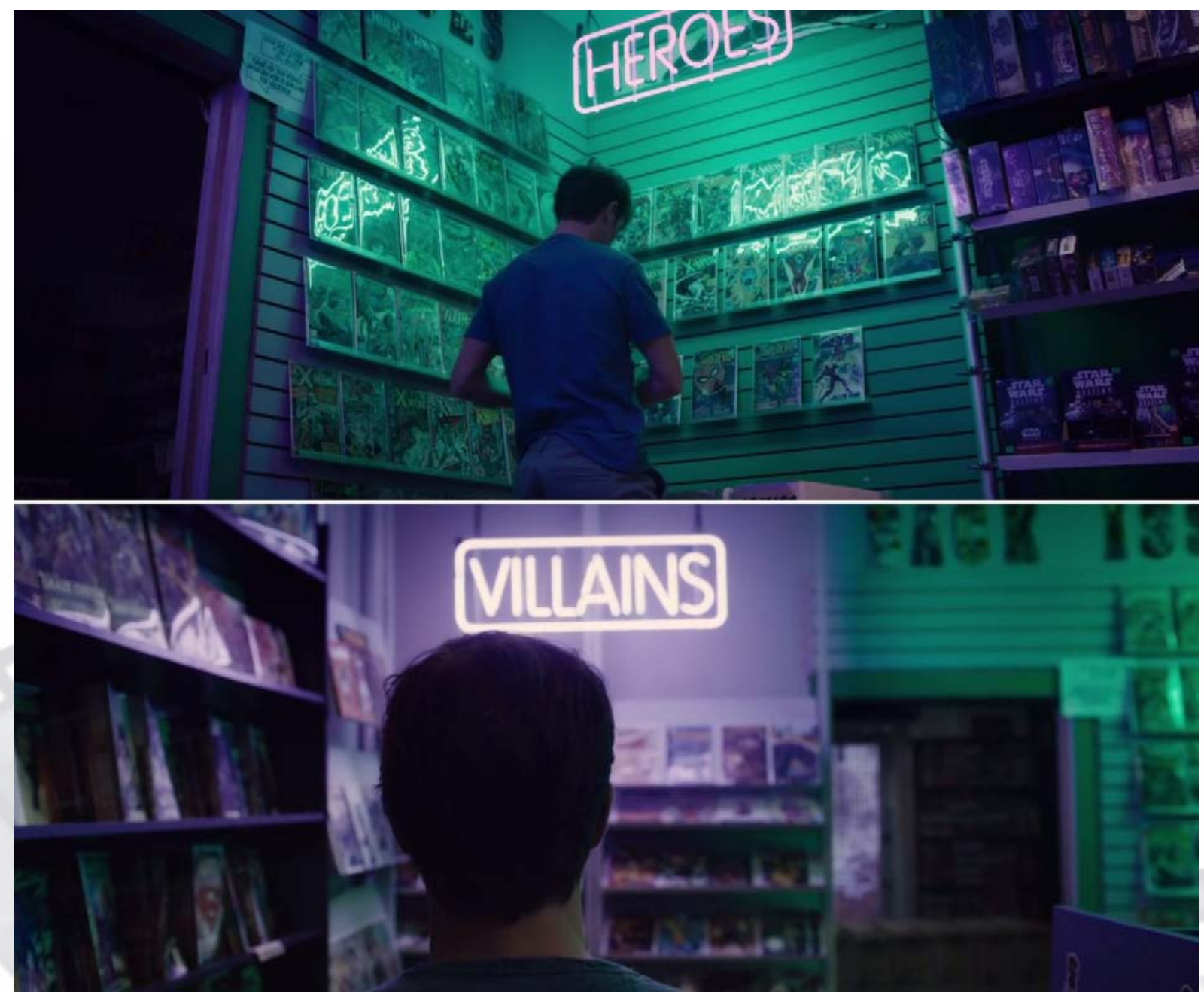

Fig. 9. Joseph Dunn y su reveladora visita a una tienda de cómics en Glass 
Al hilo de esta vinculación de Glass con los cómics de superhéroes, fijémonos a continuación en cómo se representan en sus fotogramas los tropos del género analizados ya en relación a su concurso en Unbreakable y Split:

a) Un nombre aliterativo: se mantienen los ejemplos ya vistos en la saga, pero en el caso de los nuevos personajes este aspecto es dejado de lado incluso en los apelativos de las distintas identidades de Kevin Wendell Crumb que van saliendo a la luz por vez primera. No obstante, se descubre que el padre de Kevin se llamaba Clarence W. Crumb; y sí se detecta una cierta resonancia común entre los nombres de Elijah (Price) y Ellie (Staple), el único personaje nuevo de entre los principales del relato; lo cual aporta una interesante lectura a la cinta una vez se conoce su desenlace.

b) Un alias: como ya se ha señalado con anterioridad, el nom de guerre criminal de Elijah Price es Don Cristal, inspirado por el cruel apodo con el que algunos niños se referían a él en tiempos pretéritos (tal y como se cuenta en la última y reveladora escena de Unbreakable).

c) Unos poderes específicos: frente a las habilidades esencialmente físicas de El Protector y La Bestia, Don Cristal cuenta con una mente privilegiada como habilidad principal. Tanto es así que en un momento determinante del relato se sugiere su adhesión a una tipología fundamental del género superheroico: la de «Mastermind» («Mente maestra»). A esta clase de personajes -en la que muy bien podría incluirse también a la propia Dra. Staple- pertenecen supervillanos tan veteranos como Lex Luthor, el Joker o, claro está, el propio Mente Maestra creado por Stan Lee y Jack Kirby en las páginas de uno de los primeros números de Uncanny X-Men.

d) Un aliado: Don Cristal carece de compañeros del crimen como tales, pero su naturaleza de mente maestra le permite manipular a otros personajes y convertirlos en aliados contra su voluntad. No obstante, sí aparece un sidekick en la más pura tradición de los cómics: Joseph Dunn, ya adolescente, se ha convertido en el compañero de peripecias de El Protector y el único que conoce su identidad civil. Ambos se comunican a través de micrófonos, mientras Joseph se mantiene frente al monitor del ordenador en la base de operaciones en la que se ha convertido la parte trasera de la tienda que regenta su progenitor.

e) Una némesis principal: si en un principio la contraposición de opuestos parece representada por el duelo El Protector vs. La Horda, hacia el tercio final se revela una nueva pareja de opuestos: Don Cristal vs. Dra. Staple; esta última como representante de la Black Cover Society, una sociedad secreta que durante diez mil años se ha ocupado de alejar de la opinión pública la existencia de personas con habilidades especiales, ya sea convenciendo a estas de que carecen de dichas aptitudes o bien eliminándolas como último recurso.

f) Un traje específico: hasta su reclusión en el centro psiquiátrico, se mantienen los atuendos de El Protector y de las distintas personalidades de La Horda vistos con anterioridad; pero incluso tras su ingreso entre los muros de dicha institución se mantienen los colores característicos de los tres personajes principales: verde, púrpura y amarillo [Figura 10]; unos colores que se corresponden también con los personajes secundarios vinculados a los anteriores [Figura 11]. Por su parte, a la Dra. Staple le correspondería otro color recurrente y compartido con algunos espacios de su lugar de trabajo: el rosa. 

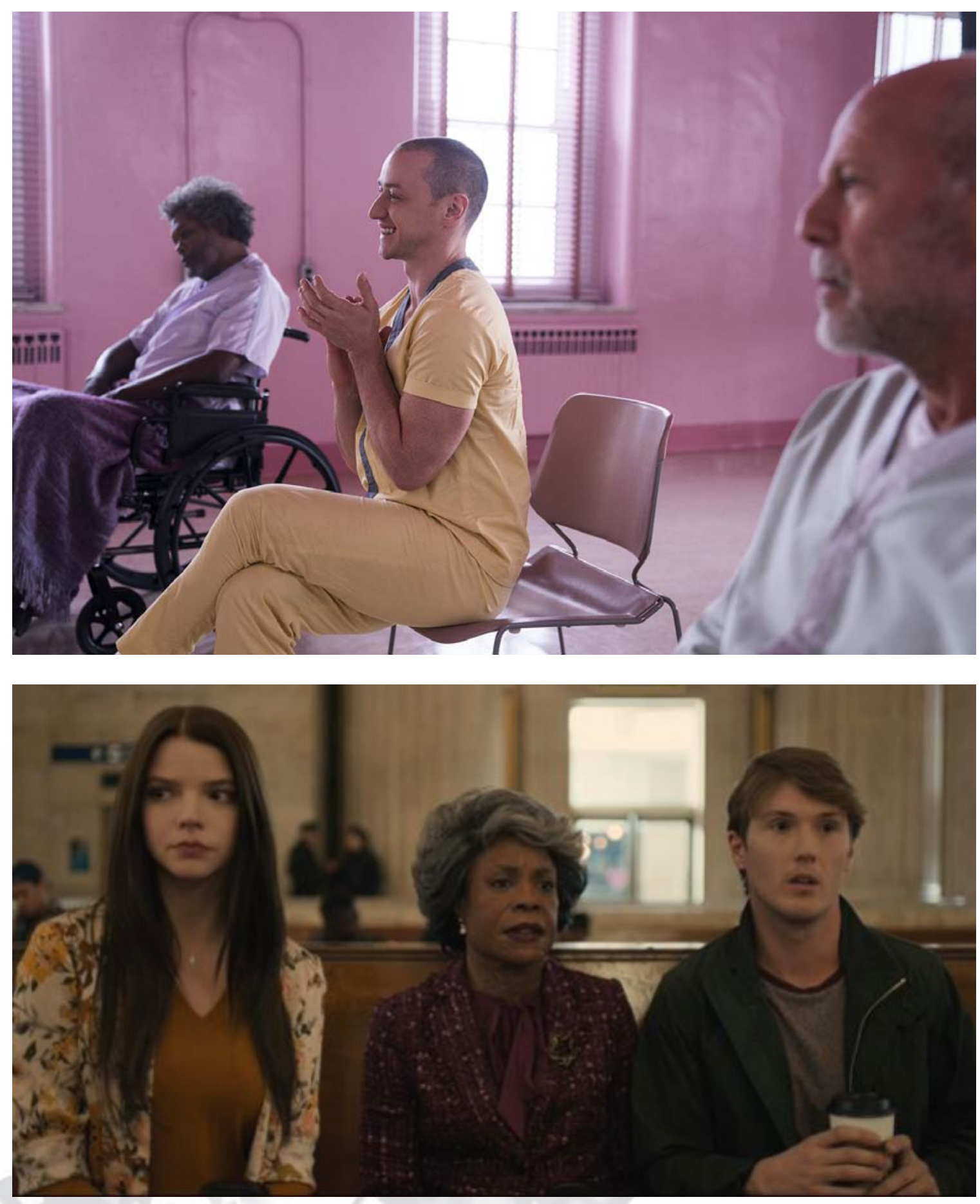

Figs. 10 y 11. El cromatismo es un aspecto muy cuidado a lo largo de toda la trilogía

g) Un punto débil: el de Don Cristal es, por supuesto, la enfermedad ósea que le define como personaje y como metáfora de una suerte de condición humana.

h) Una identidad secreta: la ruptura de este estilema del género es fundamental en la resolución del relato, en la medida en que tras el fallecimiento de los personajes principales la cuestión de la identidad secreta deja de tener sentido y, precisamente, su anulación frente a la opinión pública es aquello que trataban de impedir los verdaderos (super)villanos del relato. 
i) Un universo compartido: tras el apunte sutil de la coda final de Split, este tropo cobra su importancia fundamental en Glass, al reunir a los personajes de las dos entregas anteriores: no solo a los héroes y villanos de la trama (esto es, El Protector, Don Cristal y La Horda), sino también a civiles de importancia fundamental: de Unbreakable, Shyamalan rescata a Joseph Dunn, el hijo de David; y a la señora Price (Charlayne Woodard), madre de Elijah. En cuanto a Split, recupera a Casey Cooke y, en flashbacks, a Penelope Crumb (Rosemary Howard), la madre de Kevin... presente también junto a su hijo, encarnados ambos por intérpretes distintos y siempre según algunas teorías interpretativas no desmentidas, en la set piece de Unbreakable en la que David Dunn hace uso de su habilidad precognitiva en busca de algún criminal al que castigar hasta que descubre a El Hombre Naranja. Mención especial merece el personaje de Jai, encarnado por el propio realizador y presente en las tres películas ${ }^{14}$ : a partir de su conversación con David y Joseph, se descubre que quien aparece aquí como cliente de Dunn Home Security era el vigilante de las cámaras de seguridad del edificio de la Dra. Fletcher en Split... y también el sospechoso de traficar con drogas en el estadio donde trabajaba el protagonista en Unbreakable. Un recurso este que sirve a Shyamalan, además de para firmar sus trabajos con un guiño cómplice al estilo de su maestro Alfred Hitchcock, para dotar todavía de una mayor cohesión a su particular universo superheroico.

\section{LA CONSOLIDACIÓN DEL CINE DE SUPERHÉROES COMO GÉNERO CINEMATOGRÁFICO (2000-2019)}

Un género no existe como tal hasta que ha sido lo suficientemente codificado como para generar continuaciones, remodelaciones, pastiches y demás refritos; ya sean estos imitaciones, homenajes o parodias. Así pues, y se ha repetido hasta la saciedad, la novela de caballerías no existía -al menos en cuanto a su recepción actual- hasta que Miguel de Cervantes no la parodió en su Quijote. De igual manera, y aunque las películas protagonizadas por superhéroes vienen realizándose de forma intermitente desde hace varias décadas y de continuo durante los últimos veinte años, podría decirse que no ha sido hasta el año 2019, con la culminación de la trilogía superheroica de M. Night Shyamalan, que pueda hablarse del «cine de superhéroes» como un género a considerar como tal.

Por supuesto, esto no podría haberse conseguido en una fecha tan temprana para el asunto que nos ocupa como es el año 2000, cuando vieron la luz tanto la en muchos sentidos seminal X-Men de Bryan Singer como un trabajo tan adelantado a su tiempo como Unbreakable. Así lo considera también Monedero, que en 2012 compara el film de Shyamalan con su anterior The Sixth Sense en los siguientes términos:

14 Shyamalan se ha reservado un papel como intérprete en diez de sus trece largometrajes: al margen del rol protagonista de su olvidado debut, Praying with Anger (1992), su presencia responde a tres clases: puede ser secundaria pero fundamental en el relato, como en Signs y muy especialmente Lady in the Water; episódica, como en The Sixth Sense y las tres películas sobre las que versa este artículo; o apenas vista y/o escuchada, como en The Village, The Happening y The Last Airbender. A este respecto, véase Pons Florit, T. (2019). Cameos, el rostro como firma. En AA.VV. (2019), pp. 233-237; si bien en este artículo, a todas luces escrito antes de poder ver Glass (a la que ni siquiera cita), el autor -de forma comprensible, por otra parte- no identifica las apariciones de Shyamalan en Unbreakable y Split como las de un único personaje. 
la relación de los cómics con el resto de los medios de expresión, el cine, el teatro o la literatura está prácticamente en pañales. Por si esto fuera poco, mientras todo el mundo se ha emocionado con una historia de fantasmas, lo cierto es que no todo el mundo lee cómics y lo que es más, hay a quien ni si quiera [sic] le interesa esa cultura. No quiero decir con esto que Shyamalan estuviera apuntando a un sector del público minoritario, que no lo creo, lo que trato de explicar es que la madurez del cómic tal vez no estaba todavía preparada para que nadie subvirtiera sus códigos. O dicho de otro modo, El protegido es una película adelantada a su tiempo porque hizo con los cómics lo que El sexto sentido con los fantasmas (2012: 116-117).

En los mismos términos se refiere Noel Ceballos en un ensayo publicado en 2019 y titulado precisamente "El protegido fue una película adelantada a su tiempo»; un texto en el que su autor se refiere a la misma, además de como un «tratado sobre el comic-book entendido como mitología posmoderna», como algo para lo que «el gran público aún no estaba preparado».

Ni que decir tiene que la situación al respecto una vez alcanzado el año 2019, cuando coinciden en los cines de todo el mundo los estrenos de Glass y Avengers: Endgame -a la sazón el mayor logro de Marvel Studios hasta la fecha, y no solo por tratarse de la película más taquillera de la historia-, es bien distinta: la división de Marvel Comics encargada de llevar aquellos personajes propios de los que ostenta los derechos para su explotación audiovisual desarrolla a lo largo de un período de once años el llamado Marvel Cinematic Universe («Universo Cinematográfico Marvel») alumbrando nada menos que veintitrés largometrajes desde 2008 (año de estreno de la inaugural Iron Man y The Incredible Hulk) a 2019 (cuando llegan a los cines la citada Avengers: Endgame y Spider-Man: Far from Home, esta última a modo de epílogo de la llamada «Fase 3»); además de doce series, producidas la mitad de ellas por Netflix hasta que la recientemente creada Disney+ recoge el testigo para anunciar de inmediato ocho seriales más a estrenarse hasta $2022^{15}$. Por no hablar de los proyectos desarrollados con resultados desiguales por otras productoras, pero basados igualmente en personajes de la compañía como Spiderman, Los 4 Fantásticos, Daredevil, Elektra, el Motorista Fantasma, el Castigador, Blade o todos los relacionados con el concepto X-Men, casi un microuniverso propio; hasta llegar a la excelente cinta de animación Spider-Man: Into the Spider-Verse (2018).

En cuanto a DC Comics, no puede alcanzar la ventaja que le lleva su más directa rival, pero trata de configurar como contrapartida al imperio de aquella el denominado DC Extended Universe («Universo Extendido de DC»), y es capaz de estrenar la cifra nada desdeñable de ocho títulos desde 2013 (año de estreno de Man of Steel) hasta comienzos de 2020 (cuando ve la luz Harley Quinn: Birds of Prey) ${ }^{16}$. Además, se realizan otras películas basadas en personajes del Universo DC que quedan fuera de este canon audiovisual, sumando al menos una decena de títulos en lo que va de siglo y siendo las más destacadas las integrantes de la trilogía consagrada al personaje de Batman (2005-2012) por parte del

15 Para más información, se aconseja consultar la muy completa entrada de Wikipedia en castellano dedicada al Universo Cinematográfico Marvel: https://es.wikipedia.org/wiki/Universo cinematogr\%C3\%A1fico de Marvel.

16 Resulta aconsejable consultar la entrada de Wikipedia en castellano consagrada al Universo Extendido de DC: https://es.wikipedia.org/wiki/Universo extendido de DC 
realizador Christopher Nolan y la aplaudida Joker que dirige Todd Phillips en 2019. Todo ello sin contar el llamado DC Animated Movie Universe («Universo de Películas Animadas de DC»), donde la compañía sí le saca una considerable ventaja a Marvel en la producción de largometrajes de animación destinados a ser exhibidos en formato doméstico.

A estas versiones cinematográficas de los cómics que forman parte de los Universos Marvel y DC habría que añadir otras adaptaciones de cómics más o menos pertenecientes al género, pero ajenos a las dos grandes empresas del sector. Este es el caso de los títulos integrados en el llamado Universo Millarworld generado por el guionista Mark Millar, de los que ya se han filmado Wanted (2007), el díptico Kick-Ass (2010-2013) y tres títulos de la saga Kingsman (2014, 2017 y 2020); así como los filmes protagonizados por Hellboy (2004, 2008 y 2019), el Juez Dredd (2012) y Bloodshot (2020). Y, muy especialmente, hay que tener en cuenta aquellas películas que, como las que integran la trilogía de Shyamalan, parten de guiones originales y por tanto no inspirados (al menos, explícitamente) en material previo alguno: frente a la inmediata explotación a rebufo del éxito del Superman de 1978 -con títulos como la española Supersonic Man (1979) o la producción Disney Condorman (1981)y el caso prácticamente único de la temprana Darkman (1990) de Sam Raimi -una rareza singular en su día, tanto o más adelantada a su tiempo que Unbreakable, y que dio pie a dos secuelas estrenadas directamente en vídeo-, habría que citar en lo que llevamos de siglo las discretas My Super Ex-Girlfriend (2006), Hancock (2008) y Push (2009); las indies Special (2006), Defendor (2008) y Super (2010); la reivindicable Chronicle (2012); y el espléndido díptico de animación The Incredibles (2004-2018).

Así pues, estamos viviendo lo que Alicia Albares denomina «la era de Marvel y DC, el frenesí de las franquicias y la sobre explotación de personajes conocidos popularmente por las viñetas» (AA.VV., 2019: 87) ${ }^{17}$. A partir de todo ello, parece obvio que puede hablarse -y así sucede en los medios de comunicación en general y en la prensa especializada en particular- de un «cine de superhéroes» como concepto claramente reconocible. Y aunque afirma dejar la cuestión «para otro día», el crítico de cine Tomás Fernández Valentí plantea a las claras el asunto que nos ocupa; es decir, si el cine de superhéroes

realmente es un género (diferenciable de las dos ramas del árbol del fantástico, el terror y la ciencia ficción, y al mismo nivel que la comedia, el western o el policíaco, pongamos por caso), un subgénero (una derivación de la ciencia ficción, entendida como digresión sobre la ciencia en un contexto mítico) o una variante genérica (una rama, de nuevo, de la ciencia ficción, pero con una existencia paralela y sin integrarse por completo en ella) (2019: 6).

Lo que sí dejaremos para otro día es, siguiendo las declaraciones de este crítico, si es verdad que estamos ante «un cine, el de superhéroes [...], que si de algo cojea, en sus líneas generales y salvo contadas excepciones, es por su ausencia de estilo» (2019: 6); siendo «un cine sin estilo, o por lo menos, un cine que todavía no ha hallado su propia y reconocible estética» (2019: 7).

17 La autora continúa en estos términos: «El cómic se estaba poniendo de moda y Shyamalan lo comprendió, emprendiendo su propia y exquisita manualidad cinematográfica basada en el mismo, pero desde su mirada única» (ĺdem). 
El Quijote de los superhéroes. M. Night Shyamalan y la consolidación del cine de superhéroes como género cinematográfico

Estilo no es, desde luego, algo de lo que carezca el cine de Shyamalan en general y la hoy renombrada como «Eastrail 177 Trilogy» («Trilogía Eastrail 177»)18 en particular ${ }^{19}$. Esta obra ya está integrada en el seno de la cultura popular que comparten los aficionados al género. Tanto es así que en 2018, meses antes del estreno de Glass, su director y principales intérpretes presentaron el proyecto en la Comic-Con de San Diego (la convención anual más importante del medio) [Figura 12] ante el fervor de una legión de aficionados. Además, en dicho acto se mostró y regaló a los asistentes el afiche del film dibujado nada menos que por Alex Ross ${ }^{20}$, que muestra con su habitual estilo hiperrealista -muy apropiado dado el parejo propósito de Shyamalan- a los personajes principales de la trilogía y otros guiños al universo de las viñetas superheroicas [Figura 13].

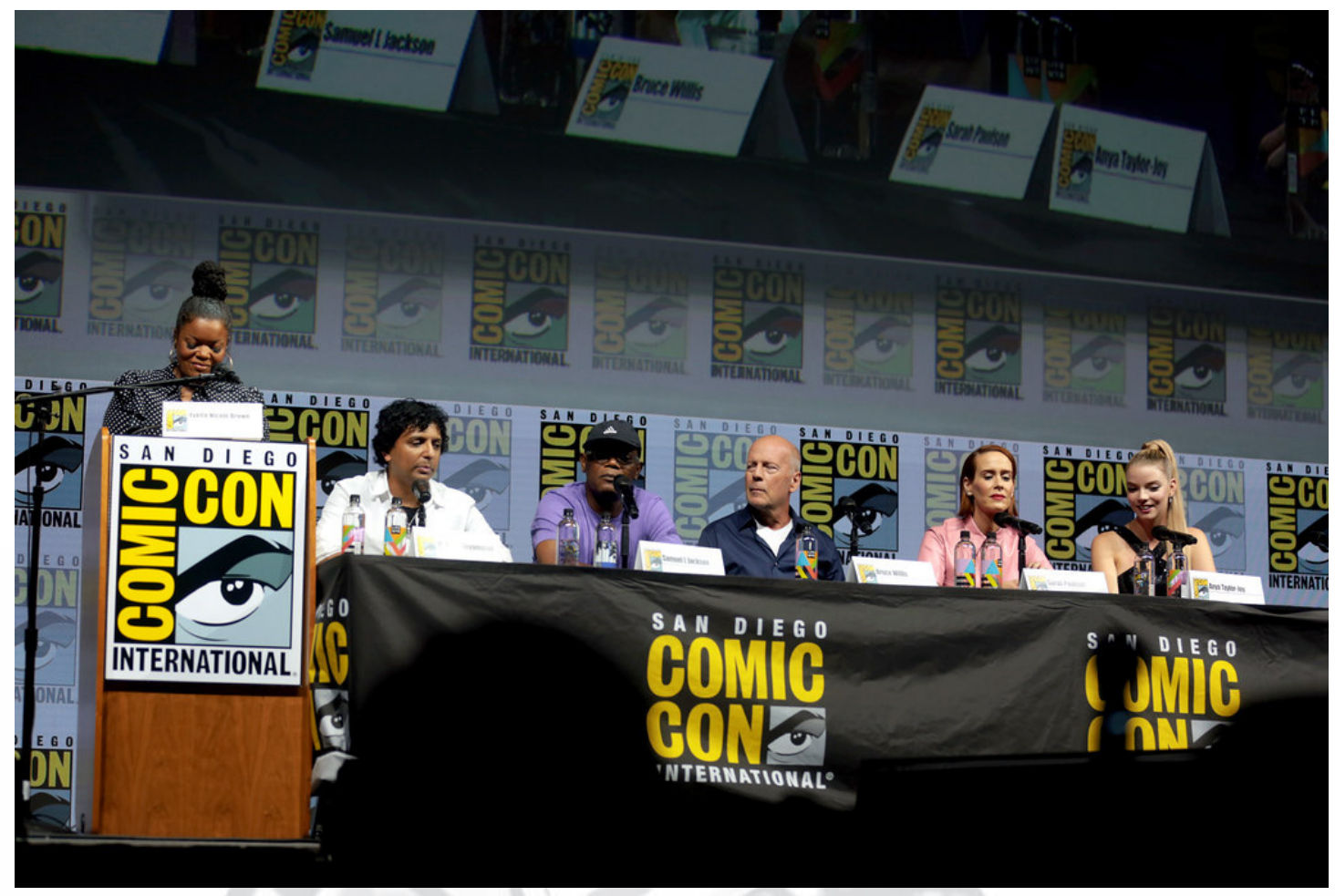

Fig. 12. Presentación de Glass en la Comic-Con de San Diego

18 Este término alude al ferrocarril que sufre un catastrófico accidente al comienzo de Unbreakable, que luego se descubrirá provocado por Elijah Price y determinante -tal y como se nos revela en Glass- para que un entonces joven Kevin Wendell Crumb termine por manifestar el trastorno de personalidad múltiple que le convertirá en La Horda; es, por tanto, un elemento de importancia capital en la trama de la trilogía al completo. Dicho término se ha empleado por parte de la prensa especializada y los seguidores más acérrimos de Shyamalan y su obra, pero no ha trascendido por el momento a la opinión pública. Por ello, muchos se refieren a esta serie de filmes como la «Unbreakable Trilogy» (dado que el personaje de David Dunn es el único presente en todos ellos) o aún más habitualmente como la "Glass Trilogy» (por ser el tercero y último el que le dota de sentido final, y el personaje de Don Cristal el verdadero agente activo detrás de los acontecimientos); que nadie parezca referirse a ella como «Split Trilogy» subraya, todavía más si cabe, el carácter secreto y a contracorriente del capítulo central.

19 Respecto al estilo visual del realizador, véase el muy ilustrativo ensayo de Reséndiz (2019).

20 A pesar de que la industria del cómic superheroico hace gala de una constante representación de lo fantástico (incluido el gusto, no siempre exento de polémica, por las anatomías imposibles), el artista estadounidense Alex Ross, de estilo hiperrealista, ha conseguido hacerse un hueco en su mercado con títulos fundamentales como Marvels y Kingdom Come, escritos respectivamente por Kurt Busiek y Mark Waid, y donde el dibujante plasma con su reconocible trazo a la plana mayor de los Universos Marvel y DC. 


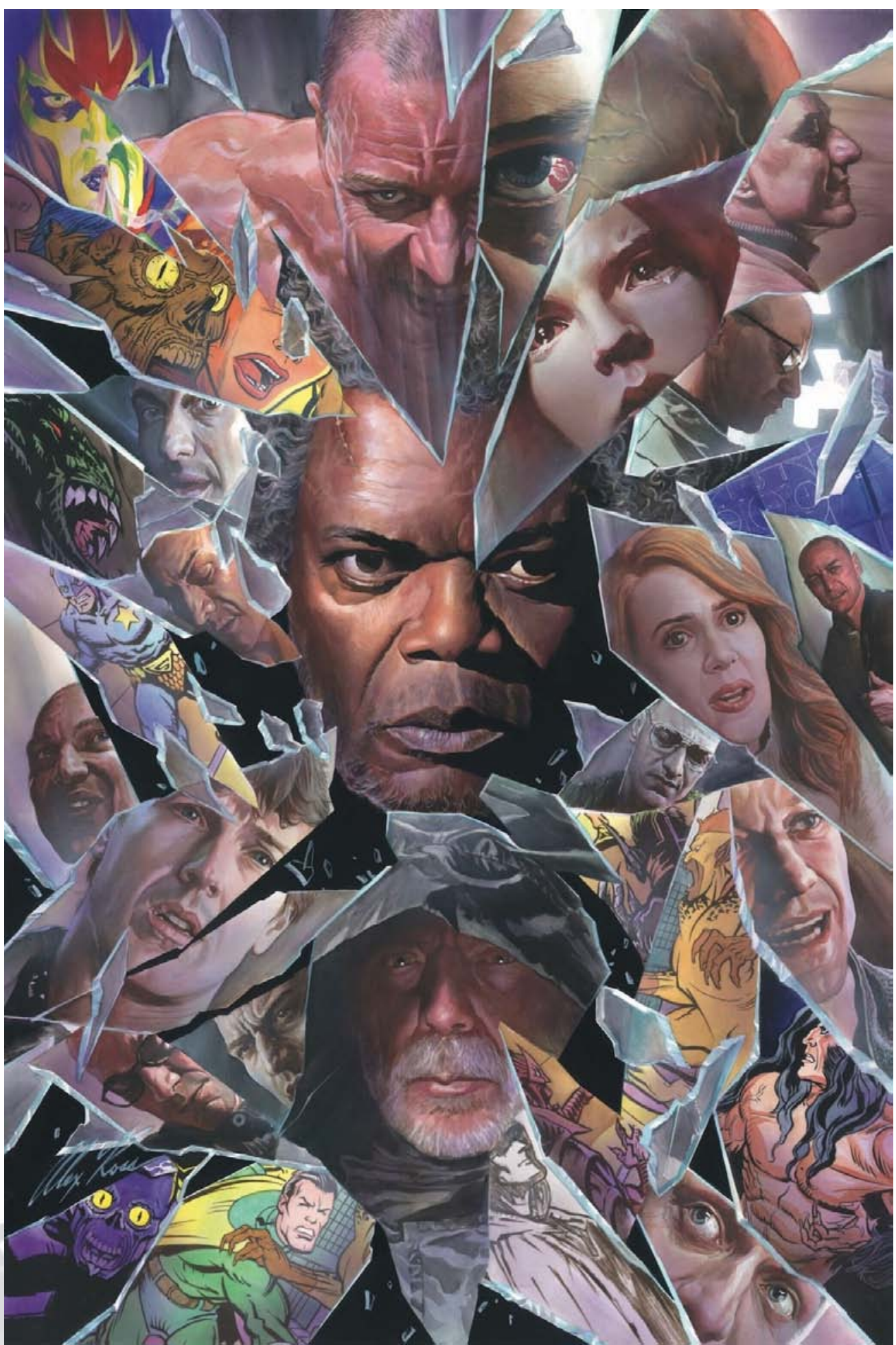

Fig. 13. La ilustración de Alex Ross realizada para la ocasión

A la hora de analizar la relación de la obra de Shyamalan con los cómics, hacemos nuestras unas palabras de Antonio José Navarro que, si bien están referidas únicamente a Unbreakable (el estudio del que se extraen se publicó en 2004, cuando Split y Glass solo existían en la mente de su futuro artífice), pueden aplicarse a la trilogía al completo: a nuestro parecer, estaríamos pues ante una propuesta 
cuya máxima osadía, al menos para los tiempos que corren, es utilizar ciertos elementos culturales poco «nobles» -cf. los cómics de superhéroes- para articular una reflexión nada moderna sobre la búsqueda de lo trascendente y el sentimiento de pérdida, de fragmentación, entre el Héroe (David Dunn) y el Único (Elijah Price), sobre lo romántico, en definitiva, como una poética esencialmente heroico-trágica (2004: 53).

No obstante, y habiendo visto ya completado el proyecto inicial de Shyamalan, añadimos una lectura más: la de la cita cervantina del comienzo de este epígrafe, de ningún modo gratuita. Porque vista en su totalidad, es fácil interpretar la historia de la «Eastrail 177 Trilogy» como una relectura en clave superheroica de los personajes más populares de la literatura española de todos los tiempos y de la obra de la que surgen. Así, Elijah Price actúa como un Alonso Quijano de la era de la globalización e Internet que enloquece fruto de la lectura de historietas de superhéroes a cuyas narraciones trata de acomodar la realidad que le rodea; por su parte, David Dunn funciona como un Sancho Panza reacio a las enseñanzas de su nuevo amigo, pero que termina dejándose arrastrar por las fantasías de aquel. La diferencia fundamental es que, en esta relectura contemporánea del mito literario, el caballero andante no solo es un (super)villano, sino que además viene a demostrar(se) finalmente -signo de la incertidumbre que define la era posmoderna- que tenía razón.

De este modo, puede decirse que si con el Quijote no solo nacía la novela moderna sino que también se dignificaban las novelas de caballerías que en principio pretendía parodiar, rescatándolas del olvido de paso, con la «Eastrail 177 Trilogy» se termina de codificar el llamado «cine de superhéroes» como género cinematográfico por derecho propio.

Por lo demás, y aunque curiosamente el cine de Shyamalan ha sido parodiado en repetidas ocasiones -las entregas primera, tercera y cuarta de la saga Scary Movie acogen referencias nada veladas a The Sixth Sense, Signs y The Village en tanto que tropos narrativos y visuales sobradamente reconocibles para el espectador iniciado ${ }^{21}$-, la «Eastrail 177 Trilogy» todavía no ha sido objeto de burlas más o menos incisivas. Decimos todavía porque, conforme vaya evolucionando el género, todo se andará... Incluida una investigación más profunda de las características de una trilogía que, dado lo reciente del estreno de su última entrega, todavía no ha sido estudiada como merece ${ }^{22}$.

21 Véase al respecto el artículo «Every Movie "Spoofed" in the Scary Movie Franchise» de Adam K. Raymond para Vulture: https://www.vulture.com/2013/04/scary-movie-franchise-every-film-spoofed-referenced.html.

22 La mayoría de trabajos de cierta enjundia sobre la filmografía de M. Night Shyamalan escritos en castellano son trabajos publicados de forma temprana que por tanto no incluyen un análisis pormenorizado de Split, mucho menos de la reciente Glass. A modo de ejemplo revelador, citaremos que en el muy interesante TFD «El ciclo del fantástico en M. Night Shyamalan» (2011) de Lourdes Domingo Domingo (Departamento de Comunicación de la Universidad Pompeu Fabra de Barcelona), una búsqueda de términos concretos en su versión en PDF de 227 páginas arroja los siguientes resultados: fantástico: 510 coincidencias; trascendental(es): 95 coincidencias; superhéroe(s): 5 coincidencias. Aclaremos que la importancia del término trascendental radica en que la autora defiende, como Navarro (2004), la tesis de que el cine de Shyamalan es una muestra de lo que podría denominarse fantástico trascendental, aludiendo al estilo que el también guionista y realizador Paul Schrader advertía en la obra de tres cineastas fundamentales en su libro, ya un clásico de la teoría cinematográfica, Transcendental Style in Film: Ozu, Bresson, Dreyer (1972). 


\section{PRESENTE Y FUTURO INMEDIATO DEL CINE DE SUPERHÉROES... Y DE M. NIGHT SHYAMALAN}

A mediados del mes de marzo de 2020, la crisis sanitaria mundial provocada por el contagio masivo del coronavirus COVID-19 cierra las salas de cine de todo el mundo y retrasa los estrenos anunciados de la producción fílmica mundial en bloque. Entre estos estrenos se encontraban los de las nuevas películas basadas en personajes de Marvel y DC, ambos por cierto femeninos: Black Widow y Wonder Woman 1984 respectivamente. Estos aplazamientos afectan en cadena a los siguientes proyectos de ambas compañías, que ahora cuentan con nuevas fechas de estreno hasta diciembre de 2022. También los rodajes de las series de la franquicia Marvel destinadas a distribuirse a través de la plataforma audiovisual Disney+ han visto atrasados sus rodajes o estrenos según sea el caso.

Al margen de Marvel y DC, otros superhéroes de papel esperan su turno para ser adaptados al cine. Este es el caso de algunos de los integrantes del llamado Universo Valiant, propiedad de la pequeña editorial del mismo nombre, y que en el momento de redactar estas líneas prepara su desembarco en la gran pantalla. Así, a la ya estrenada Bloodshot podrían sumarse adaptaciones de series como X-O Manowar, Quantum \& Woody o Faith, cuyos derechos ya están en manos de diversas productoras.

Por su parte, de M. Night Shyamalan se han anunciado dos nuevos filmes para 2021 y 2023. Dos películas de las que, como viene ocurriendo con sus últimos proyectos, la nueva información se difunde con cuentagotas y que se rodarán arropadas por el más absoluto secretismo por parte de todos los implicados. Por ahora solo ha trascendido que las vuelve a producir Universal Pictures; que de nuevo parten de guiones originales del propio realizador; que una de ellas se titulará Labor of Love; y que la otra contará con la presencia de los intérpretes Vicky Krieps, Thomasin McKenzie, Aaron Pierre, Eliza Scanlen y Alex Wolff, careciendo por el momento de estrellas en su reparto. Tampoco se ha dicho que ninguno de estos filmes tenga nada que ver con el género del cine de superhéroes, y menos aún con su «Eastrail 177 Trilogy». Pero en un principio tampoco Split parecía tener vinculación alguna con Unbreakable... por lo que apostar a que un cineasta tan dado a sorprender a su público como M. Night Shyamalan haya abandonado definitivamente el género que nos ocupa sería arriesgarse demasiado.

\section{BIBLIOGRAFÍA CITADA}

AA.VV. (2019), M. Night Shyamalan. El cineasta de cristal, Córdoba, Berenice.

AlARCÓN, T. L. (2012), Superhéroes. Del cómic al cine, Madrid, Calamar.

CEBALLOS, N. (2019), «El protegido fue una película adelantada a su tiempo». En GQ, 17///2019; https://www.revistagq.com/noticias/cultura/articulos/el-protegido-shayamalanadelantada-a-su-tiempo/32740 [consulta 3 junio 2020].

Domingo Domingo, L. (2011), El ciclo del fantástico en M. Night Shyamalan. Barcelona, Universitat Pompeu Fabra; https://www.google.com/url?sa=t\&rct=j\&q=\&esrc=s\&sourc e=web\&cd=8\&ved=2ahUKEwjl8Yv8hanpAhXdAGMBHf86B8QOFjAHegOlCBAB\&url=h ttps\%3A\%2F\%2Frepositori.upf.edu\%2Fbitstream\%2Fhandle\%2F10230\%2F12804\%2FT FD MariaLourdesDomingo.pdf\%3Fsequence\%3D1\%26isAllowed\%3Dy\&usg=AOvVaw2 K7YK3vP8BTXFDdLro oL2 [consulta 3 junio 2020]. 
Fernández VAlentí, T. (2019), «Cine de superhéroes: cuestión de estilo». En Dirigido Por 504, XI/2019, pp. 6-7.

Gómez-TARín, F. J. \& RUBio Alcover, A. (2013), «Del cineasta al imaginador. La narrativa lúdica como estrategia de supervivencia en el último M. Night Shyamalan». En: Actas $\checkmark$ Congreso Internacional Latina de Comunicación Social. San Cristóbal de La Laguna, Universidad de La Laguna; https://www.google.com/url?sa=t\&rct=j\&q=\&esrc=s\&sou

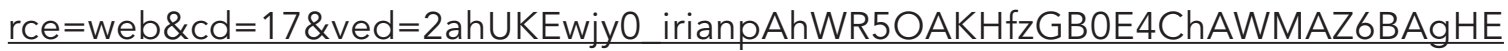
AE\&url=http\%3A\%2F\%2Fwww.revistalatinacs.org\%2F13SLCS\%2F2013 actas\%2F035 Gomez.pdf\&usg=AOvVaw3FV6aaCRd5vkd6HW8Rv6pV [consulta 3 junio 2020].

Monedero, R. (2012), M. Night Shyamalan. En ocasiones veo muertos, Madrid, Encuentro.

NAVARRO, A. J. (2004), «M. Night Shyamalan. El fantástico trascendental». En Dirigido Por 337, II/2004, pp. 44-58.

RESÉNDIZ, L. (2019), "Las dos carreras de M. Night Shyamalan». En: Letras Libres, 1/II/2019; https://www.letraslibres.com/espana-mexico/cinetv/las-dos-carreras-m-night-shyamalan [consulta 3 junio 2020]. 